\title{
REVIEW
}

\section{Remodelling of colorectal cancer cell signalling by microbiota and immunity in diabetes}

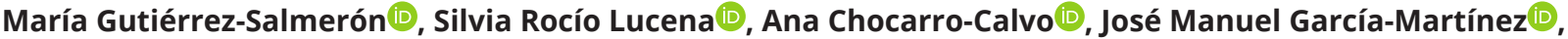 \\ Rosa M Martín Orozco and Custodia García-Jiménez
}

Area of Physiology, Faculty of Health Sciences, University Rey Juan Carlos, Alcorcón, Madrid, Spain

Correspondence should be addressed to C García-Jiménez: custodia.garcia@urjc.es

\begin{abstract}
Obesity is the strongest known risk factor to develop type 2 diabetes (T2D) and both share a state of chronic, diffuse and low-grade inflammation, impaired immune responses and alterations in the composition and function of the microbiome. Notably, these hallmarks are shared with colorectal cancer (CRC), which is epidemiologically associated to obesity and T2D. Gut barrier damages in T2D destabilize the microbiome that metabolizes the diet and modulates the host immune response triggering inflammatory and proliferative pathways. In this review, we discuss the pathways altered by defects in the immune response and microbiota that may link T2D to CRC development. Stressed adipocytes, metabolic incongruity in blood and gut barrier failure with dysbiosis cooperate to establish imbalances between immune innate and adaptive cells and cytokines such as interleukin 6 (IL6) or TNFA that define low-grade diffuse inflammation in T2D. Inflammation drives tissue repair through proliferation and migration (critical mechanisms for tumourigenesis) and under physiological conditions feeds anti-inflammatory cytokine production to resolve the process. The disproportion in pro- vs anti-inflammatory cells and cytokines imposed by T2D will impact the tumour micro- and macro-environment, favouring tumour proliferation, angiogenesis and decreased immune responses. Complex bidirectional relationships between the metabolic environment of T2D, gut microbiota, and immune dysfunctions may favour tumour cell demands and will define the outcome. Animal models developed to study the relationships between $T 2 D$ and $C R C$ in the context of microbiota and immune system are discussed.
\end{abstract}
Key Words
- diabetes and colorectal cancer
- inflammation
- cytokines and immune response
- microbiota and dysbiosis
- diet and SCFA
- murine models

\section{Introduction}

Obese and type 2 diabetic (T2D) subjects have increased risk to suffer CRC (Gutiérrez-Salmerón et al. 2017). The relative risk (RR) increases up to 1.3 (1.3-1.4) for obese subjects, and up to $1.27(1.21-1.34)$ for T2D patients; parenthesis indicates the 95\% CI.

The contribution of T2D to CRC risk is independent of obesity (Gutiérrez-Salmerón et al. 2017). Indeed, diseasefree survival data for CRC are not altered by obesity but are reduced for T2D patients, with an odd rate, $\mathrm{OR}=1.75$ (1.33-2.31) (Croft et al. 2019, Becker et al. 2020). CRC overall survival decreased by $18 \%$ in T2D patients, with 5 -year shorter survival than nondiabetic patients. Stage 2 CRC was more frequently diagnosed in T2D patients and stage 1 CRC, in nondiabetic patients (Van De Poll-Franse et al. 2007). In support of epidemiological data, analysis of 976 colonoscopies showed that T2D patients exhibit (c) 2021 Society for Endocrinology Published by Bioscientifica Ltd. Printed in Great Britain
Endocrine-Related Cancer (2021) 28, R173-R190 
a higher incidence of polyps and higher-grade dysplasia/ carcinoma (even higher in uncontrolled diabetes) when compared to nondiabetic patients (Miłek et al. 2019). Although T2D is associated to higher grade CRC, it has not been associated to particular molecular subtypes of CRC (CMS) as summarized (Gutiérrez-Salmerón et al. 2021). However, clinical adoption of CMS-based classification (integrating biological layers) to guide CRC prognosis and treatment is hampered by practical obstacles such as the influence of where the tumour samples are taken, availability of bioinformatic procedures, and the need for clinical trials to confirm their predictive value for therapy response (Buikhuisen et al. 2020).

The molecular mechanisms that link both diseases include direct impact of T2D on cancer cells and indirect effects mediated by T2D impact on the immune response and microbiome, which will, in turn, impact tumour development. The direct effects of metabolic and hormonal alterations of T2D on CRC cells are reviewed in Gutiérrez-Salmerón et al. (2021) Here, we review the potential impact for CRC of T2D-linked immune and microbiome alterations.

T2D is characterized by chronic diffuse low-grade inflammation. This could be imposed by stressed white adipose tissue (WAT) orchestrated, local and systemic changes in innate and adaptive immune components relevant for CRC (González et al. 2017, Tarasiuk et al. 2018), see Fig. 1. Increased WAT production of proinflammatory cytokines in obese/T2D patients (Kern et al. 2018), that signal through nuclear factor kappa B (NF-kB) or Janus kinases (JAK)/signal transducer and activator of transcription proteins (STAT) (West et al. 2015), feed a cycle of interactions between local and systemic immune elements leading to chronic diffuse inflammation. Remarkably, several cellular and animal models, and biopsies from patients with inflammatory bowel disease (IBD), exhibit increased pro-inflammatory cytokines and related production of reactive oxygen species (ROS) causing DNA damage and induced metalloproteinases that promote tissue remodelling. These effects play a major role in carcinogenesis (Landskron et al. 2014) and suggest an important role for inflammation in the T2DCRC link.

Long-standing observations indicate that T2D patients are more prone to infection and the course of infection is worse than for nondiabetic individuals (Alves et al. 2012). This can be attributed to advantageous growth of microorganisms in glucose-rich medium but also to T2Dassociated immune disorders. Specifically, protein and lipid glycation (advanced glycation end products: AGEs), a hallmark of $\mathrm{T} 2 \mathrm{D}$, reduce the expression of the major histocompatibility complex class I (Alves et al. 2012), decreasing antigen presentation to T lymphocytes. This may facilitate immune escape for CRC cells. Alterations in T-cell subsets and function, macrophages polarization and reduced neutrophils/eosinophils numbers illustrate immune cell disorders in T2D patients (Zhou et al. 2018) that impact colorectal carcinogenesis.

The microbiota represents itself as defence mechanism against exogenous pathogens and regulates the immune response (Belkaid \& Hand 2014). The enteric tract harbours the gut-associated lymphoid tissue (GALT) with a high number of immune cells, which will be directly impacted by the microbiota intestinal (MI). A state of dysbiosis in obesity and T2D, which also appears at the root of IBD and CRC, alters the reciprocal communication between the MI and the immune system in healthy individuals (Sonnenburg \& Bäckhed 2016). MI alterations include translocation of bacteria and their products through a damaged intestinal barrier, ensuring aberrant microbiota exposure to toll-like receptors (TLR) in fibroblasts, colon epithelial and myeloid immune cells to feed inflammation, promote cancer cell survival and proliferation and favour immune escape (Fig. 1) (Zitvogel et al. 2016). Moreover, some bacteria produce genotoxins that damage DNA favouring tumourigenesis (Schwabe \& Jobin 2013).

Immunosurveillance represents a critical barrier for tumour development potentially compromised by T2D, through MI-dependent and independent immune imbalances or dysfunction. Therefore, the characterization of MI changes in CRC (likely reflected in stool microbiota, SMI) may yield promising results.

\section{Immune response abnormalities in T2D and CRC}

The best-defined immune abnormality in obesity/T2D with an impact on CRC is chronic, low-grade inflammation. The process of inflammation is an immune response with coordinated participation of innate and adaptive immune cells and humoral components that helps to restore damaged tissues. Immune cell function requires metabolic adaptations to supply energy and biosynthetic precursors; bidirectional interactions between the immune response and metabolic environment remodel each other. Inflammation must be properly resolved to guarantee no damage to bystander tissues. Homeostasis is ensured by appropriate activation and differentiation 


\section{OBESITY}

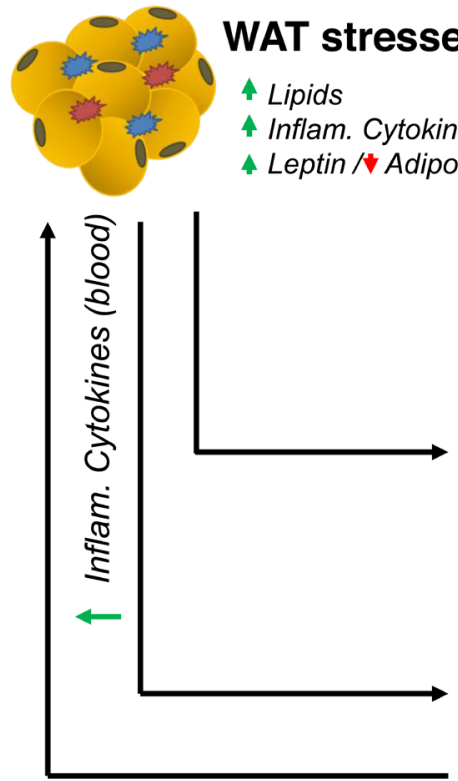

\section{DIABETES}

Pancreas exhaustion

\section{Hyperglycaemia}

4 Inflam. Cytokines (blood)

Low grade inflammation

$\downarrow$

Gut barrier dysfunction

Leak microbiome
$\uparrow$ ROS
A RNS
A AGES

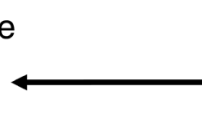

DYSBIOSIS

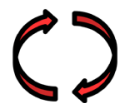

TLR interference

SYSTEMIC INFLAMMATION

UNBALANCED IMMUNE RESPONSE cellular \& humoral components

IMMUNE SURVEILLANCE

CELL TRANSFORMATION \& ANGIOGENESIS

\section{CRC}

\section{Figure 1}

Obesity and T2D are linked to CRC through microbiota and immune response alterations. In obesity, stressed adipose tissue (WAT) releases lipids, pro-inflammatory cytokines and leptin and decreases adiponectin and anti-inflammatory cytokines. This contributes to systemic low-grade inflammation and insulin resistance leading to pancreas exhaustion and T2D with hyperglycaemia. Hyperglycaemia increases cellular production of ROS, RNS and AGEs leading to endothelial dysfunction and fibrosis. Both obesity and T2D lead to gut barrier dysfunction and dysbiosis, increasing permeability to bacteria and toxins that result in increased signalling by TLR in intestinal epithelial and associated immune cells contributing to systemic inflammation. Potential contributions to CRC are imbalances from: stressed WAT (adipokines and lipids), blood (increased insulin and inflammatory cytokines, hyperglycaemia and reactive species), microbiota through barrier dysfunction (endotoxins and bacterial metabolites), immune response (with unbalanced cellular and humoral inflammatory components) and endothelial dysfunction. These factors cooperate and contribute to CRC development through decreased immune surveillance, cell transformation, metastasis and angiogenesis. AGEs, advanced glycation end products; CRC, colorectal cancer; T2D, type 2 diabetes; ROS, reactive oxygen species; RNS, reactive nitrogen species; TLR, toll-like receptor; WAT, white adipose tissue.

of immune cells (Mockler et al. 2014) and deregulation of the inflammatory process underlies malignant cell transformation in surrounding tissues (Landskron et al. 2014).

\section{WAT-originated changes in innate response linked to obesity and T2D}

WAT enlargement in obesity and the subsequently developed T2D induce mechanical and endoplasmic reticulum (ER) stress in adipocytes that release free fatty acids (FFA), adipokines and inflammatory cytokines.
This recruits and activates immune cell subsets that increase local and systemic circulating pro-inflammatory cytokines (Kern et al. 2018). Local cytokines recruit and engross the resident macrophage population and favour their polarization towards pro-inflammatory M1-like macrophages, enhancing the inflammatory response. Over recruitment of macrophages in WAT has been associated to insulin resistance and suggested to trigger T2D development in the long term (Touch et al. 2017, Zhou et al. 2018). Under physiological conditions, M2-like macrophages polarization with the secretion of anti-inflammatory cytokines (IL4, IL10, IL19) as well as 
epidermal and transforming $\beta$ growth factors: EGF and TGFB respectively, compensates M1-like polarization (Jiang et al. 2019, Kern et al. 2018) (Fig. 2).

M1/M2 imbalance in WAT of T2D patients contributes to increased pro-inflammatory cytokine secretion by adipocytes and other immune cells leading to low-grade chronic inflammation (Mauer et al. 2015) which is also a hallmark of CRC (Arcidiacono et al. 2012). Consistently, plasma levels of TNFA and IL6 were increased in obese/ T2D compared to obese or control subjects (Popko et al. 2010) (Fig. 2).
Innate lymphoid cells (ILCs) found in circulation and enriched at biological frontiers with microorganisms like the intestinal barrier or adipose tissue, represent the first defence against infections (Klose \& Artis 2020). ILCs are critical regulators of immune homeostasis, inflammation and cancer detection and their involvement in glucose homeostasis and insulin sensitivity (Huang et al. 2019) make them a interesting candidate mediators for the transition from obesity to T2D and CRC. Different ILC1, ILC2 and ILC3 subsets are reminiscent of adaptive T-cell subsets Th1, Th2 and Th17. ILC1s, including natural

\section{Immune profile}

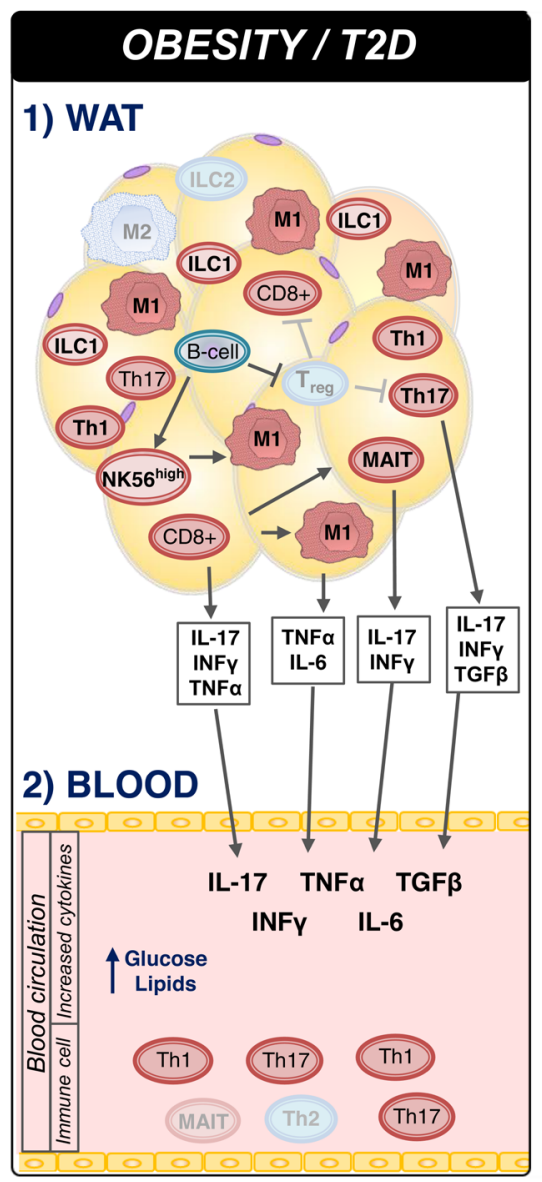

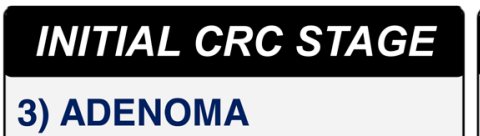

\section{ADVANCED CRC STAGE}

4) INVASIVE CARCINOMA
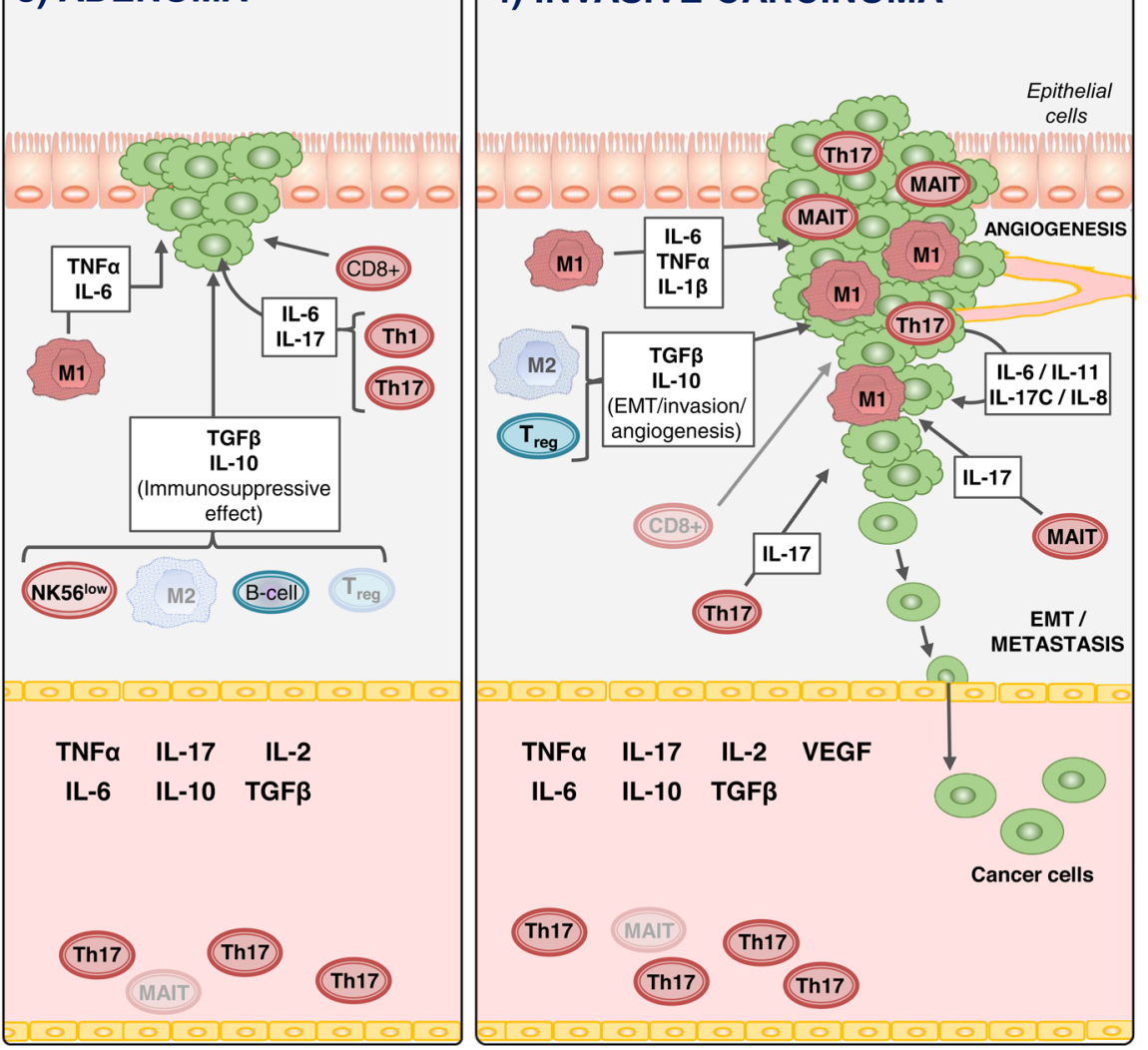

Figure 2

Cellular and humoral immune imbalances in T2D that may contribute to CRC: four relevant scenarios for CRC affected by changes in the immune response are represented: (1) WAT, (2) circulating blood, (3) initial CRC stage, (4) advanced CRC. Increased immune cells and cytokines are highlighted in bold whereas decreased cells and cytokines are labelled with grey letters. The relationships between immune cells are depicted in the WAT scenario; see main text for details. Innate and adaptive imbalances in stressed WAT by obesity/T2D increase inflammatory cells and cytokines in the blood. At initial stages of CRC, activation of cytotoxic NK56low and CD8+ T-cells of M1 macrophages must overcome tumour suppression by Treg, M2, etc. In advanced CRC stages, tumour progression is induced by over-production of IL-17 by Th17 and MAIT lymphocytes, of TGF $\beta$, IL-10 by TAMs together with increased levels of IL- 6 and TNF- $\alpha$ by TAMs and tumour cells. Note that TGF- $\beta$ and IL-10 may be anti-tumoural at initial stages and aberrantly protumoural in the cytokine environment of advanced stages favouring angiogenesis, EMT and metastasis. CRC, colorectal cancer; EMT, epithelial-to-mesenchymal transition; IL-x, interleukin-x; IFN $\gamma$, interferon $\gamma$; ILCs, innate lymphoid cells; MAIT, mucosa-associated invariant T cells. Cytotoxic NK56low (CD56low/CD16 high); immunoregulatory NK56 high: CD56high CD16low; T2D, type 2 diabetes; TAMs, tumour-associated macrophages; TILs, tumour-infiltrating lymphocytes; TNF $\alpha$, tumor necrosis factor alpha; TGF $\beta$, transforming growth factor $\beta$; VEGF, vascular endothelial growth factor; WAT, white adipose tissue.

https://erc.bioscientifica.com

https://doi.org/10.1530/ERC-20-0315 (c) 2021 Society for Endocrinology Published by Bioscientifica Ltd. Printed in Great Britain 
killer (NK), produce TNFA, IFNG, IL8, IL10; ILC2s produce IL4, IL5, IL13; ILC3s, including LTi, produce IL17 and IL22. Increased ILC1s and decreased ILC2s in WAT of obese subjects were related to decreased thermogenesis, pro-inflammatory macrophage polarization and reduced glycaemic control (Kern et al. 2018). Moreover, targeting activated ILC2s ameliorated insulin resistance in T2D (Galle-Treger et al. 2019). Consistently, T2D patient's WAT infiltrates have increased ILC1, especially NK cells and decreased ILC2 (Wang et al. 2019a). T2D induces loss of receptors NKG2D and $\mathrm{NK}_{\mathrm{p} 46}$, related to $\mathrm{NK}$ activation and cytotoxicity respectively, leading to NK dysfunction. Interestingly, human CRC samples are also highly infiltrated with NK cells, although circulating NK cells of CRC patients are phenotypically altered and dysfunctional (Huang et al. 2019), suggesting that tumour environment might alter NK cell functionality, Fig. 2. By contrast, ILC2 numbers and secretion profiles were reduced in CRC samples, reminiscent of ILC2 subsets imbalances in T2D mice. Although high ILCs plasticity and transdifferentiation dependent on cytokine environments (Huang et al. 2019) hamper the understanding of their contribution to CRC, their influence on adaptive T-cell plasticity guarantees further characterization, given the success of T-cell tumour infiltrate characterization to predict survival in CRC patients.

Thus, the innate infiltrates from WAT of T2D patients and from CRC tissue exhibit increased macrophage with unbalanced polarization, increased and dysfunctional NK and decreased ILC2.

\section{WAT-originated changes in adaptive immunity linked to obesity and T2D}

T-cell over activation in obesity has been associated with T2D progression (Zhou et al. 2018). Specific T-cell subsets that play important roles in obesity/T2D-associated inflammation exhibit altered number and activity. Increased number of activated CD4+ and CD8+ T-cells in patients with hyperglycaemia correlate with increased proinflammatory cytokine levels (Stentz \& Kitabchi 2003). CD4+ T-cells should differentiate towards suppressor (Treg) and helper cells (Th1, Th2, Th17). However, in obese T2D patients, CD4+ differentiation in WAT and blood is unbalanced towards increased production of Th1 and Th17 lymphocytes that secrete pro-inflammatory cytokines, and decreased Th2 helper and Treg cells, that produce anti-inflammatory cytokines as depicted in Fig. 3 (Zhou et al. 2018). Increased Th1, Th17 and decreased Th2 and Treg also characterize early but not advanced CRC stages (Sasidharan Nair et al. 2020). Given their suppressive role limiting CD8+ T-lymphocyte activation, reduced Treg number may cause increased CD8+ in obese T2D patients. Since B-cell deficient mice respond to obesity induction with increased Treg in WAT (Kern et al. 2018), decreased Treg number in WAT of obese patients might be linked to B-cells over-recruitment. Notably, improved insulin sensitivity in B-cell deficient mice supports a critical role for B-cell alterations underlying T2D-associated immune defects (Kern et al. 2018). Perhaps, over recruitment of B-cells and their antibodies decreases adipocyte's sensitivity to insulin. Potential development of new therapies targeting B-cells should take into account that decreasing B-cell number also limits the immune response of the patient (Winer et al. 2011).

The importance of increased WAT infiltrated CD8+ T-cells in T2D is supported by experiments in mouse models where obesity/T2D was induced by high fat diet (HFD). Increased CD8+ T-cell number in the WAT preceded macrophage accumulation and appearance of insulin resistance (Zhou et al. 2018). Among CD8+ populations, double positive T lymphocytes (CD8+ CD4+) can differentiate into invariant mucosa-associated $\mathrm{T}$ cells (MAIT), which later may lose CD4 and CD8 expression to become double negative (DN-MAIT) (Dias et al. 2018). Increased MAIT infiltration in WAT is associated with the overproduction of IL17 in obese and T2D patients (Touch et al. 2017) and IL17 levels decrease with improved glucose homeostasis upon metformin treatment, diet modifications, and exercise. In line with this, Kaplan Meier survival CRC plotting reveals a correlation between higher tumour infiltration with MAIT cells and worse prognosis (Zabijak et al. 2015). The role of MAIT cells in CRC is still debated (Berzins et al. 2020) but immunoscore based on quantification and profiling of CD8+ T-cell subsets and their location in CRC accurately predicted metastasis, disease-free and overall survival, and CD8+ are especially enriched in CMS1 subtype (Angell et al. 2020).

Thus, the adaptive infiltrates from WAT of T2D patients and from CRC tissue exhibit increased and unbalanced CD4+ T-cells (enriched with Th1, Th17 and decreased Treg, Th2). Likewise, CD8+ infiltration is increased in T2D patients WAT (likely functionally compromised due to hyperglycaemia) and in CRC tissue, especially CMS1 subtype.

Thus, as outlined in Figs 2 and 3, innate and adaptive responses in WAT and blood of T2D patients may favour CRC through cellular immune imbalances (in ILC and T-cell subsets) increasing pro-inflammatory cytokine production that feeds macrophage recruitment, M1 polarization and 


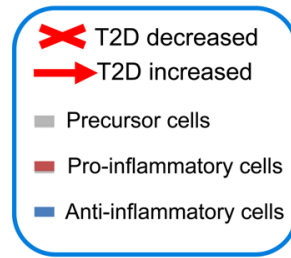

Innate immunity

Adaptative immunity

Monocyte
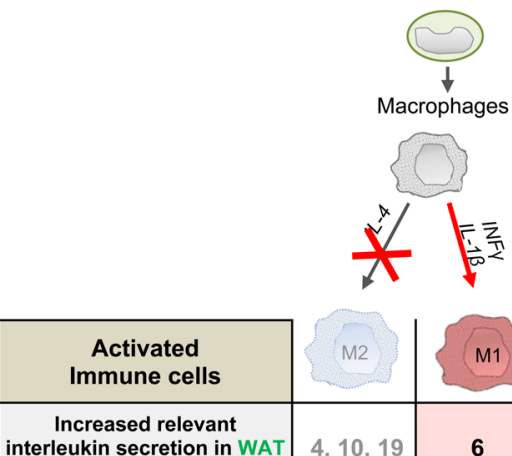

\begin{tabular}{l}
$\begin{array}{l}\text { Increased relevant } \\
\text { interleukin secretion in WAT } \\
\text { or WAT and Blood (black) }\end{array}$ \\
\hline
\end{tabular}

Others secretion

\begin{tabular}{|c|c|c|c|}
\hline Utners secretion & TGF $\beta$ & IFNy & IFNy \\
\hline Effect on insulin resistance & - & + & + \\
\hline Key signaling regulator & $\begin{array}{l}\text { AMPK I } \\
\text { STAT6 }\end{array}$ & $\begin{array}{c}\text { mTOR I } \\
\text { HIF-1 }\end{array}$ & mTORC1 \\
\hline Metabolic program & $\begin{array}{c}\text { Lipid } \\
\text { oxidation }\end{array}$ & Glycolysis & Glycolysis \\
\hline $\begin{array}{l}\text { Cell number in WAT, Blood } \\
\text { or WAT and Blood (black) }\end{array}$ & $=$ & + & $\begin{array}{l}\text { NK56 } 6^{\text {low }}- \\
\text { NK56 }\end{array}$ \\
\hline
\end{tabular}

$+$

$+\quad+\quad+$
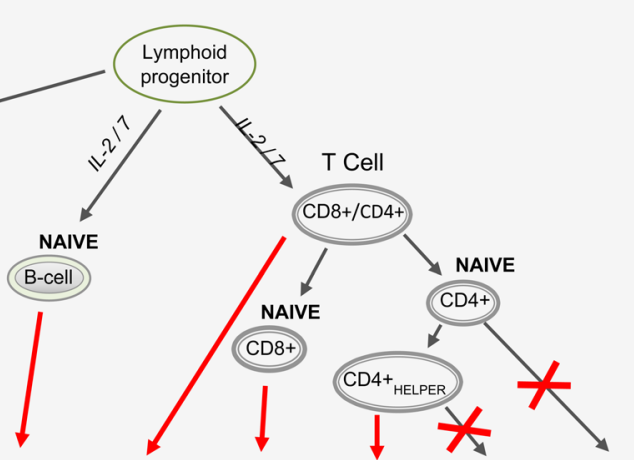

\begin{tabular}{|c|c|c|c|c|c|c|}
\hline$?$ & $\begin{array}{c}\text { PLCY I } \\
\text { ERK/ PI3K }\end{array}$ & mTORC1 & mTORC1 & $\begin{array}{c}\text { mTORC1 I } \\
\text { HIF-1 }\end{array}$ & $\begin{array}{c}\text { mTORC1/ } \\
\text { mTORC2 }\end{array}$ & AMPK \\
\hline $\begin{array}{c}\text { Lipid } \\
\text { oxidation }\end{array}$ & Glycolysis & Glycolysis & Glycolysis & Glycolysis & Glycolysis & $\begin{array}{c}\text { Lipid } \\
\text { oxidation }\end{array}$ \\
\hline
\end{tabular}

\section{Figure 3}

T2D-related alterations in immune cell differentiation and cytokine production. Upper panel: differentiation of immune innate (left) and adaptive (right) cells. Pro-inflammatory cells in red; anti-inflammatory cells in blue; precursor cells in grey. T2D-related alterations are marked with red, thick arrows (increases) or red crosses (reductions). Cell types increased by T2D are prominent and with bold letters; cell types diminished are transparent and with grey letters. Bottom panel: relevant interleukins and growth factors secreted by immune activated cells. Cytokines increased in WAT are labelled in green; if the increase has also been reported in the blood is labelled in black. Cytokines that diminish are labelled in grey. Increased (+) or decreased (-) insulin resistance and key signalling nodes and metabolic pathways activated by cytokines are indicated. Red background squares highlight T2D-increased cytokines. AMPK, AMP-activated protein kinase; EGF, epidermal growth factor; ERK, extracellular signal-regulated kinases; HIF-1, hypoxia-inducible factor $1 \alpha$; IFN $\gamma$, interferon $\gamma$; IgG, immunoglobulin G; MAIT, mucosal-associated invariant T cells; ILCs, innate lymphoid cells; ILC1 (*), not NK cells; mTOR, mammalian target of rapamycin; M1, macrophages type 1; M2, macrophages type 2; NK56high, CD56high/CD16low; NK56low, CD56low/CD16high; PI3K, phosphoinositide 3-kinase; PLC $\gamma$, phospholipase $C \gamma$; STAT6, signal transducer and activator of transcription 6; TGF- $\beta$, transforming growth factor $\beta$; TNF- $\alpha$, tumour necrosis factor $\alpha$; T2D, type 2 diabetes; WAT, white adipose tissue; (?), not studied.

increased pro-inflammatory cytokine production: IFNG, TNFA, TGFB and IL17 (Zhou et al. 2018). Inflammatory cytokines activate oncogenic signalling pathways that feed tumour cell survival, proliferation, invasion and more pro-inflammatory cytokine production (Hirano et al. 2020). CRC escape from immunosurveillance might be favoured in T2D patients by dysfunction of effector innate (NK) and adaptive (T-cells), see below.

\section{High circulating glucose and lipids remodel the immune response in T2D patients}

The metabolic environment characteristic of T2D patient's blood interferes with both innate and adaptive immune responses. Hyperglycaemia is the bestknown metabolic factor that alters immunity in T2D. Hyperglycaemia increases apoptosis and reduces the function of innate cellular components, such as antigenpresenting dendritic cells, macrophages, neutrophils and NK. Humoral innate components altered by hyperglycaemia (Wang et al. 2019a) include increased pro-inflammatory cytokines production by ILC1s and deregulated complement pathways (Daryabor et al. 2020). Adaptive humoral responses altered by hyperglycaemia include antibody class switch defects, antibody glycation (decreased ability for complement deposition) and antibody titre reduction (Daryabor et al. 2020). https://erc.bioscientifica.com

https://doi.org/10.1530/ERC-20-0315
C) 2021 Society for Endocrinology Published by Bioscientifica Ltd. Printed in Great Britain 
Adaptive immune cellular responses altered by hyperglycaemia include imbalances in lymphocyte differentiation and function that contribute to, and cooperate with, unbalanced cytokine production (Zhou et al. 2018) to favour CRC through enhanced inflammation and weakened immune surveillance. Importantly, enhanced glucose uptake allows lymphocyte 'activation' to respond to the presence of pathogens within a few hours. Indeed, high levels of glucose and lipids are critically required for proliferation, differentiation and activation of CD8+ and other immune cells (Mockler et al. 2014); preferences for glucose/glycolysis or lipid oxidation to obtain energy are highlighted in Fig. 3. T-cytotoxic cells critically depend on glucose whereas suppressor Treg cells transiently activate AMP-activated protein kinase (AMPK) to use lipid oxidation. Chronically elevated glucose and/or lipids decrease T-cell survival and activation and, therefore, hamper maintenance of a stable pool of immune cells (Mockler et al. 2014).

In vivo, hyperglycaemic rats and human patients exhibit increased lymphocyte apoptosis. In vitro, B and $\mathrm{T}$ lymphocytes differ in their transport, and response to high glucose (Oleszczak et al. 2012) but conditions of hyper- or hypo-glycaemia compared to normoglycemia, reduced glucose transport in both (Oleszczak et al. 2012), implying that lymphocyte exhibition of glucose transporters (GLUT) is regulated by glucose. Reduced glucose transport was mediated by a switch from GLUT1 and GLUT3 (with high affinity) towards GLUT4 (intermediate glucose affinity) expression, and unveils a defence mechanism against glucotoxicity (Oleszczak et al. 2012).

On the other hand, the immune cytokine milieu remodels general and immune cell metabolism as described above for ILCs. For example, IL6 signalling via JAK/STAT3 increases GLUT1 and GLUT4 levels and glycolytic enzymes: hexokinase 2 (HK2) and phosphofructokinase (PFKB3) to favour aerobic glycolysis and support high proliferation in fibroblasts (Mauer et al. 2015). The complexity of IL6 signalling cascade, activating JAK/STAT, mitogen-activated protein kinase (MAPK), phosphatidylinositol 3-kinase (PI3K) and AMPK, illustrates its important functions in metabolic control (Mauer et al. 2015). In macrophages, IL6 signalling blocks fatty acid induction of M1 macrophages and induces M2 macrophage differentiation through increased exhibition of IL4 receptors (Covarrubias \& Horng 2014). IL7 signalling through PI3K/Akt increases membrane trafficking of GLUT1 in naïve T-cells, regulating glucose uptake and critically prevents apoptosis to maintain homeostasis (Mockler et al. 2014).
Thus, metabolism and immune cells dynamically interact to maintain immune and glucose homeostasis under physiological conditions. Bidirectional remodelling under T2D conditions lessens two important barriers for CRC development, decreasing immune surveillance and increasing glucose availability for cancer cell proliferation.

\section{Inflammation cooperates with metabolism to remodel tumour infiltration in CRC}

Attempts to associate a profile of tumour-infiltrating lymphocytes (TILs) or tumour-associated macrophages (TAMs) to different CRC stages have unveiled the dynamism of the interactions. Primary CRC stage transition to advanced metastasis correlated with low CD8+ TILs density in two cohorts of 415 and 184 patients, respectively (Mlecnik et al. 2011). Consistently, low density of CD8+ TIL and high Treg density on the invasive front, were indicative of worse prognosis whereas higher CD8+ TIL densities in distant CRC metastases correlated with better prognosis (Jakubowska et al. 2019). Circulating MAITs were decreased in CRC patients and few studies attempted to profile them. However, increased MAITs in tumour infiltrates (Zabijak et al. 2015) predicted lower disease-free and overall survival by Kaplan-Meier analysis. Mixed MAIT phenotypes with the overproduction of IL17 correlated with an increased risk of developing CRC (Zabijak et al. 2015).

MAIT cell contribution to CRC progression or antitumour responses is highly debated (Berzins et al. 2020). However, most MAIT cells are recruited after the tumour is formed making it unlikely that MAIT-dependent inflammation initiates sporadic CRC. The localized inflammatory tumour microenvironment, with increased ROS that favour mutations and epigenetic changes, may lead to tumour progression (Gutiérrez-Salmerón et al. 2021). Cytokines produced inside the tumour, mainly by TILs (IL17) and TAMs (TNFA, IL6, TGFB, IL10, VEFG) and outside the tumour (in blood and/or neighbouring WAT) in T2D patients, may have an adjuvant effect on tumour progression (Landskron et al. 2014) (Fig. 2). Unbalanced cytokines such as IL6, IL7A, TGFB or TNFA may drive the transition from anti-tumourigenic to pro-tumourigenic systems through aberrant activation of STAT3/NFKB.

Analysis of 1388 CRC samples has associated characteristic immune profiles to defined CMSs, but T2D association with particular CMSs is unclear. CMS4 samples exhibit inflammatory, immunosuppressive and angiogenic signatures linked to high fibroblasts density (Becht et al. 2016). CMS1 samples, including most 
high microsatellite instability (MSI-H), over-expressed T-cell-attracting chemokines (CX3CL1, CXCL9 or CXCL10) and cytotoxic markers of CD8+ and NK cells, like WAT infiltrates of T2D patients. However, CMS1-3 subtypes are defined by immune signalling or metabolic signatures, respectively and since T2D may contribute to CRC with metabolic, signalling, immune and microbiome influences, T2D may associate with several CMSs. Perhaps, immune signatures, taken as integrated metabolic/microbiome output, may better associate T2D to CRCs subtypes.

Alternatively, CRCs have been classified according to three main pathways driving genomic instability: first, chromosomal instability (CIN); secondly, CpG island methylator phenotype (CIMP) that includes most sporadic micro satellite instable (MSI-H) cancers; thirdly, pure MSI, arising from mutations in mismatch repair genes (Worthley \& Leggett 2010). Microsatellite stability status is clinically relevant because MSI-H tumours have better stage-adjusted survival and response to chemotherapy than microsatellite stable tumours (Gupta et al. 2018). Consistent with the worse CRC prognosis for T2D patients mentioned in the introduction, MSI-H CRCs inversely associate to diabetes (Nakayama et al. 2019). Interestingly, the phenotypes distinguished by genomic instability exhibit different infiltrates and CIMP-high colon adenocarcinomas, with high lymphocyte infiltration, exhibited metabolic alterations with high glycolysis and low TCA, and it was suggested that immune infiltration contributes to direct metabolic adaptations in the tumour (Fedorova et al. 2019). These metabolic adaptations would be favoured in the context of T2D by excess circulating nutrients, but to our knowledge, CIMP and T2D have not been associated. Thus, systemic metabolism may drive infiltration as described in the previous section and immune infiltration may contribute to model metabolic adaptations in the tumour.

Chronic inflammation could drive tumourigenesis in epithelial tumour cells of T2D patients, with IL6 and TNFA increase leading to DNA damage and ER stress. Inflammation-driven ROS may drive oncogenic mutations and chromosome instability; ER-stress may drive translation-mediated phenotype-switch for tumour cell diversification (García-Jiménez \& Goding 2019). Proinflammatory cytokine imbalances in circulation in WAT and colon epithelium will impact infiltration profiles and with that tumour evolution. Association of particular profiles of TILs or TAMs to T2D is needed as biomarkers to evaluate both cancer progression and drug responses. Definition of the cellular and humoral components related to T2D that may drive immune escape will clarify their contribution to CRC initiation or progression.

In summary, increased WAT drives macrophage, ILCs and T-lymphocyte infiltration in T2D patients to develop insulin resistance leading to increased circulating glucose and lipids, that cooperate with inflammatory cytokines to further unbalance immune cell subsets. Increased WAT and blood pro-inflammatory cytokine production and signalling enhance CRC development (Bosek et al. 2018).

\section{Signalling by pro-inflammatory cytokines in CRC cells}

Which T2D-associated cytokines promote CRC and through which signalling pathways are still poorly defined. Increased IL6 and TNFA are well documented in T2D. While some cytokines have a clear pro- or anti-tumour action, most of them exert opposite effects depending on the context. IL6 activation of JAK/STAT and $\beta$-catenin signalling promote tumour proliferation, migration and angiogenesis, supporting cytokine-mediated facilitation of CRC development (Landskron et al. 2014, West et al. 2015). However, TNFA was first identified as a tumoursuppressive cytokine, but in advanced cancers, it increases ROS and reactive nitrogen species (RNS) which induce DNA damage and enhance angiogenesis and invasion (West et al. 2015). Intestinal epithelial cells express high levels of TNF receptors (TNFRs) which activate NFKB signalling. TNFR/NFKB signals through Akt-dependent glycogen synthase kinase 3B (GSK3B) inactivation to stabilize the transcription factor snail that mediates its effects on migration/invasion (West et al. 2015). Likewise, TGFB was ascribed opposite effects depending on tumour evolution. TGFB produced by Treg cells (together with IL10) to control intestinal inflammation, impairs growth and spread of cancer cells in early stages (West et al. 2015). In advanced CRC stages, TGFB induces invasiveness and metastasis (Landskron et al. 2014), mediated by IL11 induction in cancer-associated fibroblasts (CAFs). IL11 promotes STAT3 signalling in CRC cells to increase metastasis (West et al. 2015). Like TGFB, IL10 may act as pro-tumourigenic in advanced CRC, through sustained JAK/STAT3 signalling (Landskron et al. 2014).

IL2 serum levels were increased in a cohort of 79 patients with T2D and CRC compared to healthy controls (Bosek et al. 2016). IL2 increases CRC cell proliferation through IFNG induction and subsequent release of IL1, TNFA and TNFB that induced JAK/STAT, PI3K/Akt and MAPK signalling (Bosek et al. 2018). In advanced CRCs, however, increased IL2 correlated with downregulated 
Th17-related genes (Sasidharan Nair et al. 2020) suggesting a decreased inflammatory response.

Taken together, at initial tumour stages, CD4+ T-cells and macrophages-expressed cytokines inhibit tumour progression; IL22 and IL17A improve mucosa healing, microbiota management and host defence; IL21 and IL15 (from macrophages) enhance cytotoxic responses of CD8+ and NK cells and IL17F inhibits angiogenesis. By contrast, in advanced CRC stages, tumour cells contribute to interleukin production (IL6, IL11, IL17C, IL8) modulating the effects of initially anti-tumourigenic cytokines to inhibit apoptosis and promote proliferation, angiogenesis, epithelial to mesenchymal transition (EMT), metastasis and immune escape, leading to tumour progression (West et al. 2015).

Thus, as outlined in Fig. 2, the pattern and action of interleukins dynamically change along with tumour evolution and T2D-associated inflammation brings it closer to advanced CRCs.

\section{Signalling for immune escape in T2D and CRC}

The immune response against CRC offers therapeutic opportunities highlighted by the success of monoclonal antibodies against the immune inhibitory receptors: cytotoxic $\mathrm{T}$ lymphocyte-associated protein 4 (CTLA4) and programmed cell death protein 1 (PD1). CTLA4 is expressed in CD4+ T-cell subsets and PD1 is expressed on chronically activated (exhausted) T-cell subsets: CD8+ and Treg (Rotte 2019). PD1 stimulation is considered the main responsible for immune escape (Jiang et al. 2019). PD1 ligands (PD-L1) are highly expressed in tumour cells. Immunosuppression via CTLA4 or PD1 inhibits critical proliferative PI3K/Akt/mTOR signalling, decreasing glucose uptake and glycolytic flux in T-cells (Mockler et al. 2014). However, despite the high percentage (40$50 \%$ ) of PD-L1 positive cells, targeting PD1 is frustratingly inefficient in CRC (Jiang et al. 2019). Combined antiCTLA4 and PD1 (Rotte 2019) synergistically improved patient survival up to $70-80 \%$ (Overman et al. 2018), highlighting the importance of $\mathrm{CD} 4+/ \mathrm{CD} 8+$ cooperation.

Relevant for obesity/T2D and CRClinks, recent research in human patients and tumour-bearing mice unveiled paradoxical effects of obesity on CRC. Obesity increased PD-L1 expression and tumour progression (with PD1mediated T-cell dysfunction). However, increased PD-L1 in obese subjects also augments the efficacy of targeted PD1/PD-L1 therapies and survival (Wang et al. 2019b), suggesting that stratification of patients may increase successful therapeutic rates. Interestingly, abundant
PD-L1 expression also characterizes CMS1 subtype (MSIhigh). Importantly, compared to healthy subjects $(n=20)$, T2D patients $(n=23)$ did not overexpressed PD-L1 but exhibited decreased PD1 levels (Sun et al. 2019). Whether other checkpoint receptors or ligands are regulated by T2D is unknown, but the data are consistent with differential inputs from obesity and T2D to CRC.

In addition to the regulation of PD1 or CTLA4 checkpoints, immune escape might be favoured in T2D by T2D-associated dysfunction of $\mathrm{NK}$ and $\mathrm{T}$ cells induced by AGEs and imbalances in immune and microbiota components (see below).

Thus, the immune defects contributing from T2D to CRC must be defined in the blood, tumour infiltrates and perhaps, also at adipose tissue infiltrates. Blood profiles of cytokines in T2D patients should be compared to those of T2D patients with CRC at initial vs advanced stages. Similarly, TIL and TAM profiles should be compared at initial vs advanced/malignant metastasis in patients with and without T2D. The evolution of immune infiltrates in adipose tissue may help understand the links between T2D and CRC with a focus on prevention. New mass cytometry techniques offer an opportunity for detailed profiling with the potential to stratify patients that may benefit from targeted immune therapies.

\section{Interplay of diet, gut microbiota and immune response in T2D and CRC}

In healthy humans, the MI, including bacteria, fungi and protists (Saus et al. 2019), maintains a mutualistic beneficial relationship with the host; the host provides nutrients while MI modulates metabolic and immune functions to support homeostasis (Coleman et al. 2018). The MI composition is defined by the interplay of genetic and environmental factors (Torres-Fuentes et al. 2017) and aberrant host-MI interactions are prevented by the gut barrier, formed by intestinal epithelial cells joined by tight junctions and protected with a thin layer of mucin.

\section{Barrier dysfunction causes dysbiosis and alters immune response}

Weakening tight junctions and thinning the mucin layer cause barrier dysfunction and are associated with T2D (Sonnenburg \& Bäckhed 2016) and colorectal carcinogenesis (Schwabe \& Jobin 2013, Coleman \& Haller 2017). Barrier failure allows access of bacterial symbionts (c) 2021 Society for Endocrinology Published by Bioscientifica Ltd. Printed in Great Britain 
to the mucosal layer causing aberrant interactions with epithelial, stromal and immune cells, damaging the tissue and allow the growth of opportunistic bacteria producing toxins.

Hyperglycaemia disrupts the gut barrier in mice models of diabetes through GLUT2-dependent transcriptional reprogramming, leading to decreased expression of E-cadherin and zonula occludens-1 (ZO-1) to allow microbial translocation that causes aberrant lipopolysaccharide (LPS) exposure to TLR receptors, specialized in recognizing microbial products. Hyperglycaemia-induced barrier failure was also described in humans (Thaiss et al. 2018). TLR signalling in fibroblasts, myeloid and colon epithelial cells drives inflammation, enhanced survival and proliferation.

The phyla Bacteroidetes and Firmicutes constitute $90 \%$ of all bacteria in the colon of healthy individuals (Sonnenburg \& Bäckhed 2016, Chávez-Carbajal et al. 2020). Pathological conditions such as obesity, T2D or CRC cause dysbiosis: unbalanced MI composition (reflected in SMI) with changes in quantity or quality (types of bacterial populations) that alter homeostasis. Opportunistic bacterial growth further damages the epithelial barrier, increasing its permeability (Coleman $\&$ Haller 2017). Chronic inflammation in obese subjects supports bacterial population changes with reduced SMI diversity (Al-Assal et al. 2018). T2D patients additionally present increased opportunistic pathogens related to blood or digestive infections (Qin et al. 2012). Compared to healthy controls, T2D patients have less butyrate producing-bacteria (such as Clostridium butyricum), generally decreased Firmicutes and increased Bacteroidetes phylum components, according to metagenomic analysis (Chávez-Carbajal et al. 2020). Importantly, patients with CRC exhibit MI (and SMI) alterations in the same direction, with depletion of butyrate-producing bacteria and increased pro-inflammatory opportunistic pathogens (Saus et al. 2019), but changes are scaled up to reverse the proportion Firmicutes/Bacteroidetes. Note, that many bacteria from the phylum Firmicutes produce short chain fatty acids (SCFA) such as butyrate, whose anti-tumour properties are discussed below.

Impaired immune responses associated to T2D cooperate to further unbalance the MI, increasing LPS/ TLR signalling to feed forwards inflammation and allow growth of opportunistic bacteria. Unbalanced MI increases the production of pro-tumoural metabolites and genotoxins ( $\mathrm{ROS}, \mathrm{O}^{2-}$ ) that cause DNA damage and increase $\beta$-catenin tumoural signalling (Schwabe \& Jobin 2013).

Interestingly, RNA-seq metagenomics established associations between CMS subtypes and MI profiles reminiscent of immunoscore associated with particular CMSs. Figure 4 outlines major MI changes from healthy to T2D and CRC molecular subtypes.

CMS1 has an immune profile related to WAT infiltrates in T2D. CMS1 is characterized by increased bacteria from the genera Bacteroides, Hungatella and Fusobacterium. Porphyromonas gingivalis (phylum Bacteroidetes) and Fusobacterium hwasookii (very similar to Fusobacterium nucleatum) are especially abundant (Purcell et al. 2017). Fusobacterium genus also positively associates with T2D (Gurung et al. 2020). Growth of opportunistic commensal bacteria, such as F. nucleatum after MI imbalances in human CRC tissue is correlated to worse prognosis (Zheng et al. 2020). F. nucleatum increases Wnt/ $\beta$-catenin cancer cell signalling (through adhesins that decrease E-cadherin) and reduces immune surveillance on cancer cells by inhibiting NK cells. Other species enriched in CRC tissue include Bacteroides fragillis

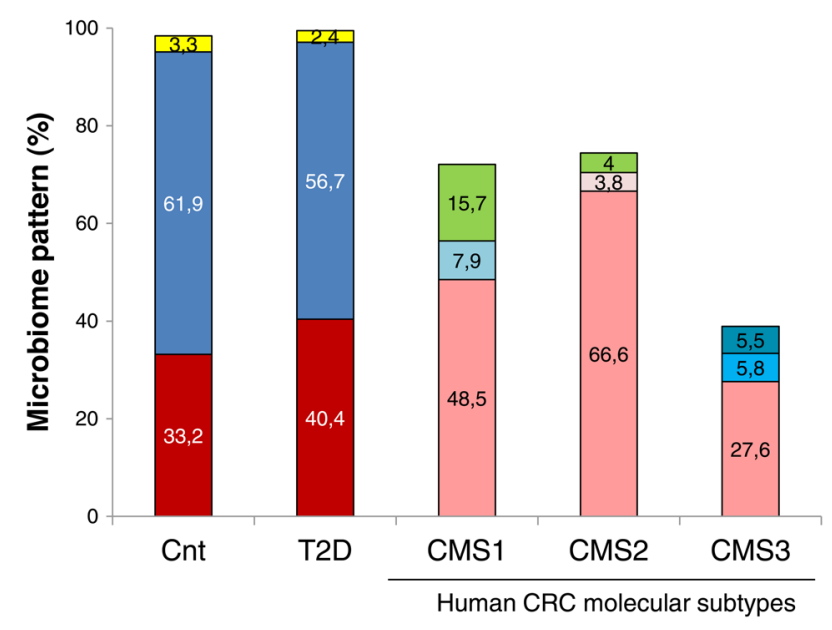

https://erc.bioscientifica.com https://doi.org/10.1530/ERC-20-0315 (c) 2021 Society for Endocrinology Published by Bioscientifica Ltd. Printed in Great Britain

$\square$ Proteobacteria
$\square$ Fusobacterium
$\square$ Firmicutes
$\square$ Faecaelibacterium
$\square$ Clostridium
$\square$ Hungatella
$\square$ Bacteroidetes
$\square$ Prevotella
$\square$ Bacteroides

\section{Figure 4}

Changes in intestinal microbiota with T2D and in colorectal cancer molecular subtypes (CMS). Main bacterial phyla and genus are represented. CMS4 is not represented because its bacterial composition is not characterized. The four main phyla (bold) in human microbiome: Proteobacteria (yellow), Fusobacterium (green), Bacteroidetes (red) and Firmicutes (blue). Relevant genera in CRC molecular subtypes are highlighted in shades of red for the Bacteroidetes phylum and with shades of blue for the Firmicutes phylum. Numbers represent the percentage of the most abundant phyla or genus in each condition. 
(phylum Bacteroidetes) that triggers inflammation (through NFKB-dependent release of pro-inflammatory chemokines) and barrier damage, through the production of the endotoxin 'fragilisin', a protease that removes E-cadherin from adherent junctions (Saus et al. 2019). The genera Faecalibacterium and Roseburia (Phylum Firmicutes) negatively associate with T2D (Gurung et al. 2020). Faecalibacterium prausnitzii and Roseburia intestinalis, which produce butyrate, are also depleted in CRC patients tissue and faeces (Qin et al. 2012) together with Eubacterium rectale. Further differences between CRC molecular subtypes are described in Fig. 4.

\section{Diet modulates barrier function and microbiota}

Diet is probably the most important environmental factor to modulate the MI (and SMI) composition and function in humans and other mammals (Sonnenburg \& Bäckhed 2016, Torres-Fuentes et al. 2017). Protein, lipids, sugar and fibre ingested are further metabolized by bacteria to render bioactive molecules. Figure 5, summarizes the main MI products and their interference with signalling pathways related to cancer cell hallmarks (Hanahan \& Weinberg 2011) and with immune responses relevant for CRC tumourigenesis (Choi \& Snider 2019).

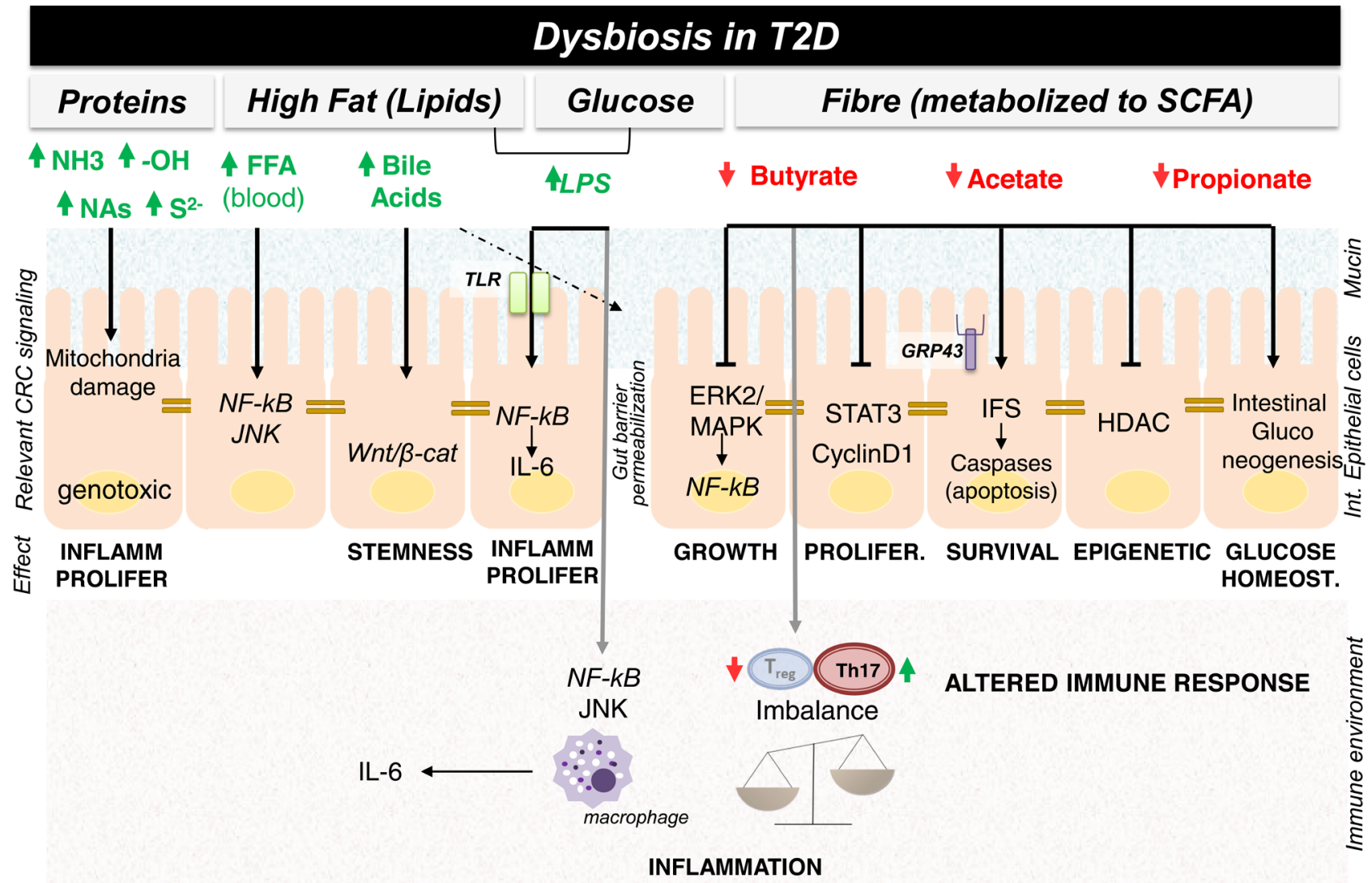

CRC

Figure 5

Contribution of dysbiosis from T2D to CRC. Intestinal epithelial cells linked by tight junctions and covered with mucin form the gut barrier that protects the microbiota and restricts its access to the diet. Alterations in microbiota populations cause dysbiosis which characterizes T2D and CRC. Protein-rich diets render increased $\mathrm{NH} 3,-\mathrm{OHs}, \mathrm{S}^{2-}$ and Nas with inflammatory and genotoxic properties to favour $\mathrm{CRC}$. High circulating glucose and fats increase LPS-producing bacteria and lead to gut barrier permeabilization and inflammation through NF-kB; Increased FFA trigger inflammatory signalling via NF-KB or JNK pathways; FFA metabolized by microbiota render SBAs that activate Wnt/ $\beta$-catenin signalling (to upregulate the expression of cancer stem cell markers) and NF-KB increasing inflammation. Fibre rich diets are metabolized to render SCFA: butyrate, acetate and propionate regulate epigenetic modifications through HDAC inhibition. Butyrate suppresses ERK2/MAPK, decreases STAT3 signalling and cyclin D1 activity to inhibit cancer cell growth. Through GRP43 receptors, butyrate activates inflammasomes. Butyrate favours Treg/Th17 balances. Propionate induces gluconeogenesis in intestinal cells to restore glucose homeostasis. CRC, colorectal cancer; ERK, extracellular signal-regulated kinases; FFA, free fatty acids; GPR43, G protein-coupled receptor 43; HDAC, histone deacetylase; IFS, inflammasomes; IL-6, interleukin 6; JNK, c-Jun N-terminal kinase; LPS, lipopolysaccharide; MAPK, mitogenactivated protein kinases; NAs, nitrosamines; NF-kB, nuclear factor kappa B; NH3, ammonia; -OH, phenols; S2-, sulphides; SCFA, short chain fatty acids; STAT3, signal transducer and activator of transcription proteins 3; TLR, toll-like receptor; T2D, type 2 diabetes. 
Diets rich in proteins increase protein fermentation at distal colon leading to accumulation of ammonia, phenols, sulphides and nitrosamines, with inflammatory and genotoxic properties which may favour CRC (Schwabe \& Jobin 2013).

High-fat and high-sucrose diets promote the extinction of several SMI bacterial populations (Koh et al. 2016), increasing the incidence of obesity, diabetes and CRC (Choi \& Snider 2019). Saturated fatty acids from HFD increase LPS producing MI bacteria, favouring inflammation among other effects. LPS trigger inflammatory pathways partly by activating TLR in intestinal epithelial cells (Rocha et al. 2016). in stromal fibroblast and in myeloid cells. LPS/TLR signalling in macrophages activates NFKB and JNK inducing the expression and secretion of more proinflammatory cytokines such as IL6 (Choi \& Snider 2019). In addition, HFD increases the production of bile acids (BA) that mediate lipids or cholesterol absorption (Ajouz et al. 2014) but are also transformed by microbiota into secondary BAs (SBAs) such as deoxycholic and lithocholic acids. SBAs disrupt E-cadherin/ $\beta$-catenin interactions and activate Wnt/ $\beta$-catenin signalling in colonic epithelial cells (Farhana et al. 2016, Choi \& Snider 2019) leading to expression of cancer stem cell markers and pluripotency genes that favour CRC tumourigenesis. Increased SBAs metabolism in T2D patients may represent another link to CRC (Torres-Fuentes et al. 2017).

T2D induced through HFD in mice reduces the levels of the most abundant antibody in mucosal surfaces, immunoglobulin A (IgA) (Luck et al. 2019). IgA is critical to discriminate pathogenic and comensal microorganisms, inducing tolerance to the host microbiota (Zheng et al. 2020) and its decrease in T2D contributes to defective immune response and MI imbalances. Diets rich in fibre potentially protect from dysbiosis (Koh et al. 2016). The main products of fibre fermentation in the gut are SCFA, taken up by normal colonocytes to provide energy, whereas CRC cells preferentially metabolize glucose through glycolysis (Wang et al. 2019c). In vitro, SCFA induce apoptosis in CRC cells through permeabilization of the lysosomal membrane, loss of mitochondrial transmembrane potential, generation of ROS and processing of caspases (Koh et al. 2016). The differences in SCFA metabolism in healthy and tumour cells must be better defined. The most abundant SCFAs produced by MI are propionate, acetate and butyrate.

Propionate production by MI activates FFA receptor 3 and inhibits histone deacetylases (HDACs) leading to induced intestinal gluconeogenesis (IGN) and generation of brain-intestinal signals that induce satiety, and increase insulin sensitivity and glucose tolerance (De Vadder et al. 2014, Koh et al. 2016), suggesting that propionate could prevent hyperglycaemia and its damages to the intestinal barrier. Acetate, produced by MI inhibits HDACs and has anti-proliferative effects (Koh et al. 2016). Butyrate inhibits HDACs (Koh et al. 2016) and protects from CRC in vitro by direct and indirect mechanisms. Butyrate decreases STAT3 and Cyclin D1 mediated proliferation of CRC cells (Chen et al. 2019) and suppresses ERK2/MAPK signalling and metastasis (Wang et al. 2019c). Butyrate also inhibits endothelial cell-specific molecule 1, a proteoglycan that activates NFKB (Kang et al. 2012). Indirect effects of butyrate on CRC include immune response modulation at the microenvironment, supported by in vitro butyrateregulated expression and signalling of TLR4 (Xiao et al. 2018). Reduced butyrate-producing bacteria in T2D may favour CRC development through these mechanisms. Dysbiosis associated to T2D (e.g. augmented LPSproducing and diminished butyrate-producing bacteria) increase NFKB signalling, that promotes inflammation in intestinal epithelial cells and favours tumour progression (Choi \& Snider 2019).

Surprisingly, SCFA also bind specific G-proteincoupled receptors: GPR41 and GPR43 that signal to activate inflammasomes, cytosolic multiprotein complexes that classically activate inflammatory caspases (Sonnenburg \& Bäckhed 2016). Mice deficient in inflammasome components have increased pro-inflammatory cytokines and microbiota abnormalities (Schwabe \& Jobin 2013) with exacerbated gut inflammatory responses and colon tumourigenesis (González et al. 2017).

Additionally, butyrate critically regulates the balance between two CD4+ T-cell subsets: suppressor Treg and proinflammatory Th17 cells. Th17 cells promote repair and neutralize pathogens when the gut barrier breaks and proper Treg/Th17 balance supports optimal host defence against pathogens (Omenetti \& Pizarro 2015). Butyrate in vitro favours Treg development and differentiation to suppress pro-inflammatory cytokines (Omenetti \& Pizarro 2015). Since HFD or T2D-associated microbiota is depleted of butyrate-producing bacteria (Koh et al. 2016), Treg population is decreased and unbalanced with Th17 increases (Fig. 5), further contributing to low-grade intestinal inflammation.

T2D is associated to decreased antitumoural SCFA production, lessening the inhibition of pro-proliferative and inflammatory TLR-signalling through STAT3/Cyclin D or ERK and NFKB (Wang et al. 2019c). MI disproportions also unbalance immune cell subsets and cause dysfunction to facilitate immune escape. 
In conclusion, T2D associated disruption of the intestinal microbiota (and its metabolites) favours CRC growth and immune escape. Diet regulation (low fat and high fibre content) could be an interesting strategy to recover microbiota in states of dysbiosis. Further research on the signalling pathways modified by microbiota will allow defining its specific role and targeting potential in the treatment of T2D and CRC. Modulation of the immune system through microbiota holds promising potential.

\section{Mouse models to study the implication of immune response and microbiota in T2D and CRC interaction}

Mouse models that clarify how the immune response affects the relationship between T2D and CRC cannot include immunosuppressed mice. Cancer cells may be allografted or CRC might be chemically or genetically induced in T2D mouse models. Alternatively, diabetes can be induced in CRC mice models, see GutiérrezSalmerón et al. (2021). These models are complicated and time-consuming but it is necessary to understand the interactions between T2D and CRC.

\section{Pro-inflammatory cytokines increased in models of obesity, T2D and CRC}

A polygenic model of diabetes, the $K K-A y$ mouse (Kleinert et al. 2018) was compared to control mice to evaluate differences in circulating pro-inflammatory adipocytokines in the serum after induction of CRC. CRC was induced by administration of azoxymethane (AOM), a procarcinogen drug that enhances ROS production, causing DNA damage in the colon. Circulating IL6, leptin and plasminogen activator inhibitor-1 were elevated in diabetic compared to control mice (Teraoka et al. 2011). The same and also monocyte chemoattractant protein-1 (MCP1) and TNFA factors increased in visceral WAT. To understand if increased circulating pro-inflammatory adipocytokines were dependent on diabetes, a Balb/c mouse model that is resistant to obesity and T2D was fed with normal or HFD with similar total calorie intake and allografted with CT26 CRC cells. Forty-two proinflammatory cytokines/chemokines and numerous angiogenesis-related proteins (VEGF, EGF, IFNG, leptin, RANTES, MCP1, etc) were increased in pooled sera of HFD fed Balb/c mice compared to mice with normal diet (Park et al. 2012). Since the proinflammatory status was achieved with HFD in non-obese/non-diabetic mice, this model may help to clarify the contribution of inflammation to CRC development.

\section{Immune cell infiltration is increased in obesity, T2D and CRC}

Tumour infiltration reflects an interaction between the tumour and the immune system, which are remodelled by the metabolic environment.

Tumour infiltration by macrophages during cancer promotion was examined in diabetic $K K-A y$ and their $K K$ control mice after CRC induction with AOM. $K K-A y$ diabetic mice developed more tumours than controls, and tumour tissue presented higher macrophage infiltration (increased F4/80 markers) and activation (increased IL1B and osteopontin). Other increased factors relevant for CRC were colony stimulating factor 1 and MCP1, which induce proliferation, differentiation and infiltration (Ito et al. 2013).

The contribution of tumour cells to the immune response was studied in Balb/c mice allografted with CT26 cells and fed with HFD or normal diet but allowing similar calories. HFD increased macrophage infiltration of adipose tissue, at least in the epididymal fat (Park et al. 2012), and modulated macrophage polarization.

The C57BL/6 mice model that becomes obese and diabetic upon HFD feeding and develops gut barrier dysfunction has been used for CRC induction with combined AOM and dextran sulphate sodium, a general pro-inflammatory agent. Immune cell recruitment and activation enhanced CRC highlighted the contribution of microbiota. In this model, CRC promotion was mediated by exposure of IL6-polarized macrophages to commensal antigens. Expression of the chemokine CCL-20 that recruits CCR-6-expressing lymphocytes modulated tumour microenvironment (Wunderlich et al. 2018).

\section{Microbiota modification modulates CRC}

The interference of altered microbiota in T2D with CRC development was evaluated in a genetic model for CRC, the $A p c^{M i n}$ mouse, that develop intestinal polyps; T2D was induced by HFD. Comparison of gut microbiota in $A p c$ mutant mice with or without T2D revealed different tumour growth, immune response and microbiota. Indigenous microbiota replacement with $C$. butyricum partially suppressed CRC through modulation of gut microbiota and interference with Wnt/ $\beta$-catenin (c) 2021 Society for Endocrinology Published by Bioscientifica Ltd. Printed in Great Britain 


\begin{tabular}{|c|c|c|c|c|}
\hline & $\begin{array}{l}\text { Outstanding } \\
\text { question }\end{array}$ & \multicolumn{2}{|l|}{ How to approach them } & Clinical implications \\
\hline & \multirow{2}{*}{$\begin{array}{l}\text { Define the specific } \\
\text { effects of T2D on } \\
\text { immune cells }\end{array}$} & \multirow{2}{*}{$\begin{array}{l}\text { Mass cytometry } \\
\text { Liquid biopsies } \\
\text { Bioplex }\end{array}$} & $\begin{array}{l}\text { Define impaired } \\
\text { immune factors } \\
\text { in T2D in blood } \\
\text { and WAT }\end{array}$ & \multirow{2}{*}{$\begin{array}{l}\text { Improved patient stratification } \\
\text { and management } \\
\text { Potential for preventive and } \\
\text { therapeutic strategies }\end{array}$} \\
\hline & & & $\begin{array}{l}\text { Biomarker } \\
\text { establishment. }\end{array}$ & \\
\hline \multirow{10}{*}{ 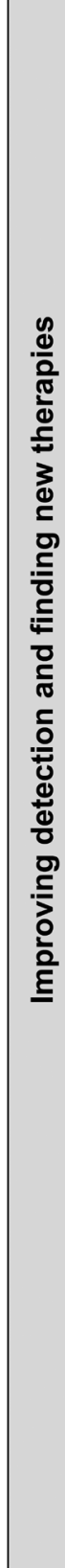 } & \multirow{3}{*}{$\begin{array}{l}\text { Identify the } \\
\text { contribution of } \\
\text { impaired immune } \\
\text { response in T2D to } \\
\text { CRC }\end{array}$} & \multirow{2}{*}{$\begin{array}{l}\text { Flow cytometry } \\
\text { Mass cytometry } \\
\text { Bioplex multiplex gene } \\
\text { expression }\end{array}$} & \multirow{2}{*}{$\begin{array}{l}\text { Define immune } \\
\text { profiles that link } \\
\text { T2D to CRC } \\
\text { (initial vs } \\
\text { advanced) } \\
\text { Explore immune } \\
\text { profiles in } \\
\text { tumour, blood } \\
\text { and WAT }\end{array}$} & $\begin{array}{l}\text { Expand immune checkpoint } \\
\text { blockade therapies (e.g. PD1 } \\
\text { or CTLA-4) }\end{array}$ \\
\hline & & & & $\begin{array}{l}\text { Improvement of tumour } \\
\text { infiltrating lymphocytes } \\
\text { therapies }\end{array}$ \\
\hline & & RNA-seq and proteomics & $\begin{array}{l}\text { Relate immune } \\
\text { profiles of T2D } \\
\text { to CMS1-4 }\end{array}$ & $\begin{array}{l}\text { Potential for combined } \\
\text { therapies }\end{array}$ \\
\hline & \multirow{2}{*}{$\begin{array}{l}\text { Define changes in } \\
\text { microbiota that } \\
\text { impact on CRC }\end{array}$} & $\begin{array}{l}\text { Metagenomics to } \\
\text { characterize microbiome } \\
\text { profile }\end{array}$ & \multirow{2}{*}{$\begin{array}{l}\text { Detection of } \\
\text { dysbiosis } \\
\text { markers in } \\
\text { faeces that can } \\
\text { be used as early } \\
\text { biomarkers }\end{array}$} & \multirow[t]{2}{*}{ Improve early CRC detection } \\
\hline & & Faecal bacteria analysis & & \\
\hline & \multirow[t]{2}{*}{$\begin{array}{l}\text { Define the role of } \\
\text { dysbiosis in the } \\
\text { T2D/CRC link }\end{array}$} & \multirow{2}{*}{$\begin{array}{l}\text { Development of CRC mice } \\
\text { models with dysbiosis in } \\
\text { the absence of obesity or } \\
\text { diabetes } \\
\text { Is a bidirectional } \\
\text { relationship? }\end{array}$} & $\begin{array}{l}\text { Understanding } \\
\text { the immune / } \\
\text { microbiome } \\
\text { interactions in } \\
\text { physiological } \\
\text { context }\end{array}$ & \multirow{2}{*}{$\begin{array}{l}\text { Improved management of } \\
\text { patients and potential for } \\
\text { microbiome-targeted } \\
\text { strategies }\end{array}$} \\
\hline & & & $\begin{array}{l}\text { Identify critical } \\
\text { microbiome } \\
\text { components }\end{array}$ & \\
\hline & \multirow{3}{*}{$\begin{array}{l}\text { Explore the } \\
\text { therapeutic } \\
\text { potential of } \\
\text { microbiome } \\
\text { interventions for } \\
\text { T2D and/or CRC }\end{array}$} & $\begin{array}{l}\text { Use of high fibre/low fat } \\
\text { diets and probiotics in } \\
\text { animal models }\end{array}$ & \multirow{3}{*}{$\begin{array}{l}\text { Understanding } \\
\text { dysbiosis }\end{array}$} & \multirow{2}{*}{$\begin{array}{l}\text { Potential of new generation } \\
\text { antibiotics to avoid } \\
\text { opportunistic overgrowth }\end{array}$} \\
\hline & & $\begin{array}{l}\text { Explore epidemiology of } \\
\text { extreme human diets for } \\
\text { T2D, CRC and their } \\
\text { treatments }\end{array}$ & & \\
\hline & & Faecal transplants & & $\begin{array}{l}\text { Potential of faecal transplant } \\
\text { for T2D and as adjuvant for } \\
\text { CRC }\end{array}$ \\
\hline
\end{tabular}

Figure 6

Outstanding questions and future perspectives. The more relevant questions to be approached in the near future in order to understand the contribution to CRC of an altered immune response and microbiota in T2D are highlighted. This will help to improve early CRC detection and to develop new therapies. CMS, CRC molecular subtypes; CRC, colorectal cancer; CTLA4, cytotoxic T lymphocyte antigen 4; HFD, high fat diet; PD1, programmed cell death 1; T2D, type 2 diabetes; WAT, white adipose tissue. 
signalling (Chen et al. 2020). In this model, Berberine, an extensively used anti-infection agent, restored microbiota alterations, especially the Verrucomicrobia and protected against CRC by diminishing $\beta$-catenin and cyclin D1 protein levels (Wang et al. 2018) suggesting that berberine can be useful as a coadjutant therapy.

Interestingly, induction of T2D in $A p c^{M i n}$ mice by HFD or by crossing $A p c$ mice with leptin signalling deficient mice $d b d b$ complicated the conclusions. The number and size of intestinal tumours were bigger in the $d b d b$ model and both models differed in their immune response and gut microbiota (Pfalzer et al. 2016). The results suggest that leptin signalling defective mice $(d b d b)$ carry additional defects compared to HFD. Gut microbiome (faecal microbiome and metabolome) rendered distinct patterns for HFD and $d b d b$ diabetic models. Mice with tumours displayed a reduction in the species Parabacteroides distasonis, with anti-inflammatory effects in the colon. Moreover, the relative abundance of $P$. distasonis inversely correlated with increased colonic production of the inflammatory cytokine IL1B. Also, according to its predicted anti-inflammatory role, adenosine levels were reduced and inversely associated with colonic IL1B and TNFA production in tumour-bearing mice (Pfalzer et al. 2015). Transcriptomic analysis revealed similarities and differences between T2D induction by HFD or genetically $(d b d b)$. A considerable overlap was revealed between both models, with Akt as the major common target (Pfalzer et al. 2016). Curiously, the most relevant differing signalling pathways were related to immune and inflammatory responses.

The immune response and intestinal microbiota composition are intimately linked by bidirectional interactions and altered in T2D and CRC. Understanding the origin and timing of these changes will reveal complex connections between T2D and CRC and may help to find better/easier prevention tools and antitumoural therapeutic interventions. The remodelling of MI by the diet adds another level of complexity but also possibilities for intervention. Mouse models with T2D and CRC are extremely important to study the indirect impact of T2D on CRC initiation and progression through diet, microbiota and immune response.

\section{Conclusions and future perspectives}

Undeniable bidirectional relationships between the immune system, intestinal microbiota and metabolism are reflected in diseases like obesity, T2D or CRC. Immune defects associated with T2D present in the initial stages of CRC may facilitate tumourigenesis and immune escape. Promising results of immune therapies encourage immune profiling of patients with T2D and/or CRC. Immune profiling including TILs and TAMs profiles at different CRC stages, and circulating blood and perhaps adipose tissue may also help to identify critical defects and develop more efficient therapies. Adjuvant therapies directed to metabolism might be combined with targeted PD1 immunotherapy (Wang et al. 2019b) to increase success against CRC in T2D patients.

MI interactions with tumour cells and their environment including immune cells modulate proliferation and inflammation, both crucial for CRC development. The Human Microbiome Project, developed to characterize microbiota in healthy volunteers, helps to understand the impact of microbiota on diabetes, cancer and other human pathologies. However, knowledge is still insufficient to characterize the complexity of specific microbial communities among different diseases. The study of faeces and faecal transplants suggests that the regulation of bacterial levels (and their products, i.e. SCFA) holds promise for the treatment of dysbiosis, at the root of diabetes and CRC and, therefore, for early diagnosis and prognosis improvement.

At present, there are no specific screening, therapeutic or follow-up protocols for T2D patients with CRC. Colonoscopy or SMI screening in T2D may have a big preventive impact and would be very informative.

Figure 6 summarizes outstanding questions, promising approaches and expected clinical outcomes from a better understanding of the impact of T2Drelated immune and microbiome alterations in CRC development.

\section{Declaration of interest}

The authors declare that there is no conflict of interest that could be perceived as prejudicing the impartiality of this review.

\section{Funding}

The financial support of the Spanish government (Grant Nos. AEl, Mineco/FEDER SAF2016-79837-R and PID2019-110998RB-I00) is gratefully acknowledged. A C-C was supported by Comunidad de Madrid: Ayudas Atracción de Talento (2017-T1/BMD-5334). S R L was supported by Comunidad de Madrid/FEDER-PEJD-2017-POST/BMD-3906.

\section{References}

Ajouz H, Mukherji D \& Shamseddine A 2014 Secondary bile acids: an underrecognized cause of colon cancer. World Journal of Surgical Oncology 12 164. (https://doi.org/10.1186/1477-7819-12-164) (c) 2021 Society for Endocrinology Published by Bioscientifica Ltd. Printed in Great Britain 
Al-Assal K, Martinez AC, Torrinhas RS, Cardinelli C \& Waitzberg D 2018 Gut microbiota and obesity. Clinical Nutrition Experimental 20 60-64. (https://doi.org/10.1016/j.yclnex.2018.03.001)

Alves C, Casqueiro J \& Casqueiro J 2012 Infections in patients with diabetes mellitus: a review of pathogenesis. Indian Journal of Endocrinology and Metabolism 16 (Supplement 1) 27. (https://doi. org/10.4103/2230-8210.94253)

Angell HK, Bruni D, Carl Barrett JC, Herbst R \& Galon J 2020 The immunoscore: colon cancer and beyond. Clinical Cancer Research 26 332-339. (https://doi.org/10.1158/1078-0432.CCR-18-1851)

Arcidiacono B, Iiritano S, Nocera A, Possidente K, Nevolo MT, Ventura V, Foti D, Chiefari E \& Brunetti A 2012 Insulin resistance and cancer risk: an overview of the pathogenetic mechanisms. Experimental Diabetes Research 2012 789174. (https://doi. org/10.1155/2012/789174)

Becht E, De Reyniès A, Giraldo NA, Pilati C, Buttard B, Lacroix L, Selves J, Sautès-Fridman C, Laurent-Puig P \& Fridman WH 2016 Immune and stromal classification of colorectal cancer is associated with molecular subtypes and relevant for precision immunotherapy. Clinical Cancer Research 22 4057-4066. (https://doi. org/10.1158/1078-0432.CCR-15-2879)

Becker DJ, Iyengar AD, Punekar SR, Kaakour D, Griffin M, Nicholson J \& Gold HT 2020 Diabetes mellitus and colorectal carcinoma outcomes: a meta-analysis. International Journal of Colorectal Disease $\mathbf{3 5}$ 1989-1999. (https://doi.org/10.1007/s00384-020-03666-z)

Belkaid Y \& Hand TW 2014 Role of the microbiota in immunity and inflammation. Cell 157 121-141. (https://doi.org/10.1016/j. cell.2014.03.011)

Berzins SP, Wallace ME, Kannourakis G \& Kelly J 2020 A role for MAIT cells in colorectal cancer. Frontiers in Immunology 11 949. (https:// doi.org/10.3389/fimmu.2020.00949)

Bosek I, Sulich A \& Rabijewsk MR 2016 Levels of interleukin-2 in patients with colon cancer and diabetes type 2. Journal of Pre-Clinical and Clinical Research 10 1-5. (https://doi. org/10.5604/18982395.1201825)

Bosek I, Kuczerowski R, Miłek T, Rabijewski M, Kaleta B, Kniotek M, Ciostek P \& Piatkiewicz P 2018 The levels of interleukin-2 and interleukin-10 in patients with type 2 diabetes and colon cancer. Clinical Diabetology 7 114-121. (https://doi.org/10.5603/ DK.2018.0006)

Buikhuisen JY, Torang A \& Medema JP 2020 Exploring and modelling colon cancer inter-tumour heterogeneity: opportunities and challenges. Oncogenesis 9 66. (https://doi.org/10.1038/s41389-020-00250-6)

Chávez-Carbajal A, Pizano-Zárate ML, Hernández-Quiroz F, OrtizLuna GF, Morales-Hernández RM, De Sales-Millán A, HernándezTrejo M, García-Vite A, Beltrán-Lagunes L, Hoyo-Vadillo C, et al. 2020 Characterization of the gut microbiota of individuals at different T2D stages reveals a complex relationship with the host. Microorganisms $\mathbf{8}$ 94. (https://doi.org/10.3390/microorganisms8010094)

Chen J, Zhao KN \& Vitetta L 2019 Effects of intestinal microbialelaborated butyrate on oncogenic signaling pathways. Nutrients $\mathbf{1 1}$ 1026. (https://doi.org/10.3390/nu11051026)

Chen D, Jin D, Huang S, Wu J, Xu M, Liu T, Dong W, Liu X, Wang S, Zhong W, et al. 2020 Clostridium butyricum, a butyrate-producing probiotic, inhibits intestinal tumor development through modulating Wnt signaling and gut microbiota. Cancer Letters 469 456-467. (https://doi.org/10.1016/j.canlet.2019.11.019)

Choi S \& Snider AJ 2019 Diet, lipids and colon cancer. International Review of Cell and Molecular Biology 347 105-144. (https://doi. org/10.1016/bs.ircmb.2019.07.001)

Coleman OI \& Haller D 2017 Bacterial signaling at the intestinal epithelial interface in inflammation and cancer. Frontiers in Immunology 8 1927. (https://doi.org/10.3389/fimmu.2017.01927)

Coleman OI, Lobner EM, Bierwirth S, Sorbie A, Waldschmitt N, Rath E, Berger E, Lagkouvardos I, Clavel T, McCoy KD, et al. 2018 Activated ATF6 induces intestinal dysbiosis and innate immune response to promote colorectal tumorigenesis. Gastroenterology 155 1539.e121552.e12. (https://doi.org/10.1053/j.gastro.2018.07.028)

Covarrubias AJ \& Horng T 2014 IL-6 strikes a balance in metabolic inflammation. Cell Metabolism 19 898-899. (https://doi. org/10.1016/j.cmet.2014.05.009)

Croft B, Reed M, Patrick C, Kovacevich N \& Voutsadakis IA 2019 Diabetes, obesity, and the metabolic syndrome as prognostic factors in stages I to III colorectal cancer patients. Journal of Gastrointestinal Cancer 50 221-229. (https://doi.org/10.1007/s12029-018-0056-9)

Daryabor G, Atashzar MR, Kabelitz D, Meri S \& Kalantar K 2020 The effects of type 2 diabetes mellitus on organ metabolism and the immune system. Frontiers in Immunology 11 1582. (https://doi. org/10.3389/fimmu.2020.01582)

De Vadder F, Kovatcheva-Datchary P, Goncalves D, Vinera J, Zitoun C, Duchampt A, Bäckhed F \& Mithieux G 2014 Microbiota-generated metabolites promote metabolic benefits via gut-brain neural circuits. Cell 156 84-96. (https://doi.org/10.1016/j.cell.2013.12.016)

Dias J, Boulouis C, Gorin JB, Van Den Biggelaar RHGA, Lal KG, Gibbs A, Loh L, Gulam MY, Sia WR, Bari S, et al. 2018 The CD4-CD8- MAIT cell subpopulation is a functionally distinct subset developmentally related to the main CD8+ MAIT cell pool. PNAS $\mathbf{1 1 5}$ E11513-E11522. (https://doi.org/10.1073/pnas.1812273115)

Farhana L, Nangia-Makker P, Arbit E, Shango K, Sarkar S, Mahmud H, Hadden T, Yu Y \& Majumdar APN 2016 Bile acid: a potential inducer of colon cancer stem cells. Stem Cell Research and Therapy $\mathbf{7} 181$. (https://doi.org/10.1186/s13287-016-0439-4)

Fedorova MS, Krasnov GS, Lukyanova EN, Zaretsky AR, Dmitriev AA, Melnikova NV, Moskalev AA, Kharitonov SL, Pudova EA, Guvatova ZG, et al. 2019 The CIMP-high phenotype is associated with energy metabolism alterations in colon adenocarcinoma. $B M C$ Medical Genetics 20 52. (https://doi.org/10.1186/s12881-019-0771-5)

Galle-Treger L, Sankaranarayanan I, Hurrell BP, Howard E, Lo R, Maazi H, Lewis G, Banie H, Epstein AL, Hu P, et al. 2019 Costimulation of type-2 innate lymphoid cells by GITR promotes effector function and ameliorates type 2 diabetes. Nature Communications 10 713. (https://doi.org/10.1038/s41467-01908449-x)

García-Jiménez C \& Goding CR 2019 Starvation and pseudo-starvation as drivers of cancer metastasis through translation reprogramming. Cell Metabolism 29 254-267. (https://doi.org/10.1016/j. cmet.2018.11.018)

González N, Prieto I, del Puerto-Nevado L, Portal-Nuñez S, Ardura JA, Corton M, Fernández-Fernández B, Aguilera $\mathrm{O}$, Gomez-Guerrero C, Mas S, et al. 20172017 update on the relationship between diabetes and colorectal cancer: epidemiology, potential molecular mechanisms and therapeutic implications. Oncotarget 8 18456-18485. (https://doi.org/10.18632/oncotarget.14472)

Gupta R, Sinha S \& Paul RN 2018 The impact of microsatellite stability status in colorectal cancer. Current Problems in Cancer 42 548-559. (https://doi.org/10.1016/j.currproblcancer.2018.06.010)

Gurung M, Li Z, You H, Rodrigues R, Jump DB, Morgun A \& Shulzhenko N 2020 Role of gut microbiota in type 2 diabetes pathophysiology. EBiomedicine 51 102590. (https://doi.org/10.1016/j.ebiom.2019.11.051)

Gutiérrez-Salmerón M, Chocarro-Calvo A, García-Martínez JM, de la Vieja A \& García-Jiménez C 2017 Epidemiological bases and molecular mechanisms linking obesity, diabetes, and cancer Endocrinologia, Diabetes y Nutricion 64 109-117. (https://doi. org/10.1016/j.endinu.2016.10.005)

Gutiérrez-Salmerón M, Lucena SR, Chocarro-Calvo A, GarcíaMartínez JM, Martín Orozco RM \& García-Jiménez C 2021 Metabolic and hormonal remodeling of colorectal cancer cell signalling by diabetes. Endocrine-Related Cancer 28 191-206. (https://doi. org/10.1530/ERC-21-0092)

Hanahan D \& Weinberg RA 2011 Hallmarks of cancer: the next generation. Cell 144 646-674. (https://doi.org/10.1016/j. cell.2011.02.013) https://erc bioscientifica.com

https://doi.org/10.1530/ERC-20-0315 (c) 2021 Society for Endocrinology Published by Bioscientifica Ltd. Printed in Great Britain 
Hirano T, Hirayama D, Wagatsuma K, Yamakawa T, Yokoyama Y \& Nakase H 2020 Immunological mechanisms in inflammation associated colon carcinogenesis. International Journal of Molecular Sciences 21 3062. (https://doi.org/10.3390/ijms21093062)

Huang Q, Cao W, Mielke LA, Seillet C, Belz GT \& Jacquelot N 2019 Innate lymphoid cells in colorectal cancers: a double-edged sword. Frontiers in Immunology 10 3080. (https://doi.org/10.3389/ fimmu.2019.03080)

Ito K, Ishigamori R, Mutoh M, Ohta T, Imai T \& Takahashi M 2013 Ay allele promotes azoxymethane-induced colorectal carcinogenesis by macrophage migration in hyperlipidemic/diabetic KK mice. Cancer Science 104 835-843. (https://doi.org/10.1111/cas.12162)

Jakubowska K, Koda M, Kisielewski W, Kańczuga-Koda L \& Famulski W 2019 Tumor-infiltrating lymphocytes in primary tumors of colorectal cancer and their metastases. Experimental and Therapeutic Medicine 18 4904-4912. (https://doi.org/10.3892/etm.2019.8146)

Jiang X, Wang J, Deng X, Xiong F, Ge J, Xiang B, Wu X, Ma J, Zhou M, Li X, et al. 2019 Role of the tumor microenvironment in PD-L1/ PD-1-mediated tumor immune escape. Molecular Cancer 1810. (https://doi.org/10.1186/s12943-018-0928-4)

Kang YH, Ji NY, Han SR, Lee CIl, Kim JW, Yeom YIl, Kim YH, Chun HK, Kim JW, Chung JW, et al. 2012 ESM-1 regulates cell growth and metastatic process through activation of NF-кB in colorectal cancer. Cellular Signalling 24 1940-1949. (https://doi.org/10.1016/j. cellsig.2012.06.004)

Kern L, Mittenbühler MJ, Vesting AJ, Ostermann AL, Wunderlich CM \& Wunderlich FT 2018 Obesity-induced TNF $\alpha$ and IL-6 signaling: the missing link between obesity and inflammation-driven liver and colorectal cancers. Cancers 1124 . (https://doi.org/10.3390/ cancers11010024)

Kleinert M, Clemmensen C, Hofmann SM, Moore MC, Renner S, Woods SC, Huypens P, Beckers J, De Angelis MH, Schürmann A, et al. 2018 Animal models of obesity and diabetes mellitus. Nature Reviews: Endocrinology 14 140-162. (https://doi.org/10.1038/ nrendo.2017.161)

Klose CSN \& Artis D 2020 Innate lymphoid cells control signaling circuits to regulate tissue-specific immunity. Cell Research 30 475-491. (https://doi.org/10.1038/s41422-020-0323-8)

Koh A, De Vadder F, Kovatcheva-Datchary P \& Bäckhed F 2016 From dietary fiber to host physiology: short-chain fatty acids as key bacterial metabolites. Cell 165 1332-1345. (https://doi.org/10.1016/j. cell.2016.05.041)

Landskron G, De La Fuente M, Thuwajit P, Thuwajit C \& Hermoso MA 2014 Chronic inflammation and cytokines in the tumor microenvironment. Journal of Immunology Research 2014149185. (https://doi.org/10.1155/2014/149185)

Luck H, Khan S, Kim JH, Copeland JK, Revelo XS, Tsai S, Chakraborty M, Cheng K, Tao Chan Y, Nøhr MK, et al. 2019 Gutassociated IgA+ immune cells regulate obesity-related insulin resistance. Nature Communications 10 3650. (https://doi.org/10.1038/ s41467-019-11370-y)

Mauer J, Denson JL \& Brüning JC 2015 Versatile functions for IL-6 in metabolism and cancer. Trends in Immunology 36 92-101. (https:// doi.org/10.1016/j.it.2014.12.008)

Miłek T, Forysiński K, Myrcha P \& Ciostek P 2019 Diabetes association of polyps and colon cancer. Polski Przeglad Chirurgiczny 91 9-12. (https://doi.org/10.5604/01.3001.0013.2588)

Mlecnik B, Tosolini M, Kirilovsky A, Berger A, Bindea G, Meatchi T, Bruneval P, Trajanoski Z, Fridman WH, Pagès F, et al. 2011 Histopathologic-based prognostic factors of colorectal cancers are associated with the state of the local immune reaction. Journal of Clinical Oncology 29 610-618. (https://doi.org/10.1200/ JCO.2010.30.5425)

Mockler MB, Conroy MJ \& Lysaght J 2014 Targeting T cell immunometabolism for cancer immunotherapy; understanding the impact of the tumor microenvironment. Frontiers in Oncology 4107. (https://doi.org/10.3389/fonc.2014.00107)

Nakayama Y, Iijima T, Wakaume R, Takahashi K, Matsumoto H, Nakano D, Miyaki M \& Yamaguchi T 2019 Microsatellite instability is inversely associated with type 2 diabetes mellitus in colorectal cancer. PLOS ONE 14 e0215513. (https://doi.org/10.1371/journal.pone.0215513)

Oleszczak B, Szablewski L \& Pliszka M 2012 The effect of hyperglycemia and hypoglycemia on glucose transport and expression of glucose transporters in human lymphocytes B and T: an in vitro study. Diabetes Research and Clinical Practice 96 170-178. (https://doi. org/10.1016/j.diabres.2011.12.012)

Omenetti S \& Pizarro TT 2015 The Treg/Th17 axis: a dynamic balance regulated by the gut microbiome. Frontiers in Immunology 6639. (https://doi.org/10.3389/fimmu.2015.00639)

Overman MJ, Lonardi S, Wong KYM, Lenz HJ, Gelsomino F, Aglietta M, Morse MA, Van Cutsem E, McDermott R, Hill A, et al. 2018 Durable clinical benefit with nivolumab plus ipilimumab in DNA mismatch repair-deficient/microsatellite instability-high metastatic colorectal cancer. Journal of Clinical Oncology 36 773-779. (https://doi. org/10.1200/JCO.2017.76.9901)

Park H, Kim M, Kwon GT, Lim DY, Yu R, Sung MK, Lee KW, Daily JW \& Park JHY 2012 A high-fat diet increases angiogenesis, solid tumor growth, and lung metastasis of CT26 colon cancer cells in obesityresistant BALB/c mice. Molecular Carcinogenesis 51 869-880. (https:// doi.org/10.1002/mc.20856)

Pfalzer AC, Nesbeth PD, Parnell LD, Iyer LK, Liu Z, Kane AV, Chen CY, Tai AK, Bowman TA, Obin MS, et al. 2015 Diet- and geneticallyinduced obesity differentially affect the fecal microbiome and metabolome in Apc1638N mice. PLoS ONE 10 e0135758. (https:// doi.org/10.1371/journal.pone.0135758)

Pfalzer AC, Kamanu FK, Parnell LD, Tai AK, Liu Z, Mason JB \& Crott JW 2016 Interactions between the colonic transcriptome, metabolome, and microbiome in mouse models of obesity-induced intestinal cancer. Physiological Genomics 48 545-553. (https://doi.org/10.1152/ physiolgenomics.00034.2016)

Popko K, Gorska E, Stelmaszczyk-Emmel A, Plywaczewski R, Stoklosa A, Gorecka D, Pyrzak B \& Demkow U 2010 Proinflammatory cytokines IL- 6 and TNF- $\alpha$ and the development of inflammation in obese subjects. European Journal of Medical Research 15 (Supplement 2) 120-122. (https://doi.org/10.1186/2047-783X-15-S2-120)

Purcell RV, Visnovska M, Biggs PJ, Schmeier S \& Frizelle FA 2017 Distinct gut microbiome patterns associate with consensus molecular subtypes of colorectal cancer. Scientific Reports 7 11590. (https://doi. org/10.1038/s41598-017-11237-6)

Qin J, Li Y, Cai Z, Li S, Zhu J, Zhang F, Liang S, Zhang W, Guan Y, Shen D, et al. 2012 A metagenome-wide association study of gut microbiota in type 2 diabetes. Nature 490 55-60. (https://doi. org/10.1038/nature11450)

Rocha DM, Caldas AP, Oliveira LL, Bressan J \& Hermsdorff HH 2016 Saturated fatty acids trigger TLR4-mediated inflammatory response. Atherosclerosis 244 211-215. (https://doi.org/10.1016/j. atherosclerosis.2015.11.015)

Rotte A 2019 Combination of CTLA-4 and PD-1 blockers for treatment of cancer. Journal of Experimental \& Clinical Cancer Research 38255. (https://doi.org/10.1186/s13046-019-1259-z)

Sasidharan Nair V, Saleh R, Taha RZ, Toor SM, Murshed K, Ahmed AA, Kurer MA, Abu Nada M, Al Ejeh F \& Elkord E 2020 Differential gene expression of tumor-infiltrating CD4+ T cells in advanced versus early stage colorectal cancer and identification of a gene signature of poor prognosis. OncoImmunology 9 1825178. (https://doi.org/10.1080 /2162402X.2020.1825178)

Saus E, Iraola-Guzmán S, Willis JR, Brunet-Vega A \& Gabaldón T 2019 Microbiome and colorectal cancer: roles in carcinogenesis and clinical potential. Molecular Aspects of Medicine 69 93-106. (https:// doi.org/10.1016/j.mam.2019.05.001) (c) 2021 Society for Endocrinology Published by Bioscientifica Ltd. Printed in Great Britain 
Schwabe RF \& Jobin C 2013 The microbiome and cancer. Nature Reviews: Cancer 13 800-812. (https://doi.org/10.1038/nrc3610)

Sonnenburg JL \& Bäckhed F 2016 Diet-microbiota interactions as moderators of human metabolism. Nature 535 56-64. (https://doi. org/10.1038/nature18846)

Stentz FB \& Kitabchi AE 2003 Activated T lymphocytes in Type 2 diabetes: implications From in vitro studies. Current Drug Targets 4 493-503. (https://doi.org/10.2174/1389450033490966)

Sun P, Jin Q, Nie S, Jia S, Li Y, Li X \& Guo F 2019 Unlike PD-L1, PD-1 is downregulated on partial immune cells in type 2 diabetes. Journal of Diabetes Research 2019 5035261. (https://doi. org/10.1155/2019/5035261)

Tarasiuk A, Mosińska P \& Fichna J 2018 The mechanisms linking obesity to colon cancer: an overview. Obesity Research and Clinical Practice $\mathbf{1 2}$ 251-259. (https://doi.org/10.1016/j.orcp.2018.01.005)

Teraoka N, Mutoh M, Takasu S, Ueno T, Nakano K, Takahashi M, Imai T, Masuda S, Sugimura T \& Wakabayashi K 2011 High susceptibility to azoxymethane-induced colorectal carcinogenesis in obese KK-Ay mice. International Journal of Cancer 129 528-535. (https://doi. org/10.1002/ijc.25711)

Thaiss CA, Levy M, Grosheva I, Zheng D, Soffer E, Blacher E, Braverman S, Tengeler AC, Barak O, Elazar M, et al. 2018 Hyperglycemia drives intestinal barrier dysfunction and risk for enteric infection. Science 359 1376-1383. (https://doi.org/10.1126/ science.aar3318)

Torres-Fuentes C, Schellekens H, Dinan TG \& Cryan JF 2017 The microbiota-gut-brain axis in obesity. Lancet. Gastroenterology and Hepatology 2 747-756. (https://doi.org/10.1016/S24681253(17)30147-4)

Touch S, Clément K \& André S 2017 T cell populations and functions are altered in human obesity and Type 2 diabetes. Current Diabetes Reports 17 81. (https://doi.org/10.1007/s11892-017-0900-5)

Van De Poll-Franse LV, Houterman S, Janssen-Heijnen MLG, Dercksen MW, Coebergh JWW \& Haak HR 2007 Less aggressive treatment and worse overall survival in cancer patients with diabetes: a large population based analysis. International Journal of Cancer 120 1986-1992. (https://doi.org/10.1002/ijc.22532)

Wang H, Guan L, Li J, Lai M \& Wen X 2018 The effects of berberine on the gut microbiota in Apc min/+ mice fed with a high fat diet. Molecules 23 2298. (https://doi.org/10.3390/molecules23092298)

Wang H, Shen L, Sun X, Liu F, Feng W, Jiang C, Chu X, Ye X, Jiang C, Wang Y, et al. 2019a Adipose group 1 innate lymphoid cells promote adipose tissue fibrosis and diabetes in obesity. Nature Communications 10 3254. (https://doi.org/10.1038/s41467-019-11270-1)
Wang Z, Aguilar E, Luna J, Dunai C, Khuat LT, Le CT, Mirsoian A, Minnar M, Stoffel KM, Sturgill IR, et al. 2019b Paradoxical effects of obesity on $\mathrm{T}$ cell function during tumor progression and PD-1 checkpoint blockade. Nature Medicine 201925 141-151. (https://doi. org/10.1038/s41591-018-0221-5)

Wang G, Yu Y, Wang YZ, Wang JJ, Guan R, Sun Y, Shi F, Gao J \& Fu XL 2019 c Role of SCFAs in gut microbiome and glycolysis for colorectal cancer therapy. Journal of Cellular Physiology 234 17023-17049. (https://doi.org/10.1002/jcp.28436)

West NR, Mccuaig S, Franchini F \& Powrie F 2015 Emerging cytokine networks in colorectal cancer. Nature Reviews: Immunology $\mathbf{1 5}$ 615-629. (https://doi.org/10.1038/nri3896)

Winer DA, Winer S, Shen L, Wadia PP, Yantha J, Paltser G, Tsui H, Wu P, Davidson MG, Alonso MN, et al. 2011 B cells promote insulin resistance through modulation of $\mathrm{T}$ cells and production of pathogenic IgG antibodies. Nature Medicine 17 610-617. (https://doi. org/10.1038/nm.2353)

Worthley DL \& Leggett BA 2010 Colorectal cancer: molecular features and clinical opportunities. Clinical Biochemist: Reviews 31 31-38.

Wunderlich CM, Ackermann PJ, Ostermann AL, Adams-Quack P, Vogt MC, Tran ML, Nikolajev A, Waisman A, Garbers C, Theurich S, et al. 2018 Obesity exacerbates colitis-associated cancer via IL-6regulated macrophage polarisation and CCL-20/CCR-6-mediated lymphocyte recruitment. Nature Communications 9 1646. (https://doi. org/10.1038/s41467-018-03773-0)

Xiao T, Wu S, Yan C, Zhao C, Jin H, Yan N, Xu J, Wu Y, Li C, Shao Q et al. 2018 Butyrate upregulates the TLR4 expression and the phosphorylation of MAPKs and NK-кB in colon cancer cell in vitro. Oncology Letters 16 4439-4447. (https://doi.org/10.3892/ ol.2018.9201)

Zabijak L, Attencourt C, Guignant C, Chatelain D, Marcelo P, Marolleau JP \& Treiner E 2015 Increased tumor infiltration by mucosal-associated invariant $\mathrm{T}$ cells correlates with poor survival in colorectal cancer patients. Cancer Immunology, Immunotherapy 64 1601-1608. (https://doi.org/10.1007/s00262-015-1764-7)

Zheng D, Liwinski T \& Elinav E 2020 Interaction between microbiota and immunity in health and disease. Cell Research 30 492-506. (https://doi.org/10.1038/s41422-020-0332-7)

Zhou T, Hu Z, Yang S, Sun L, Yu Z \& Wang G 2018 Role of adaptive and innate immunity in type 2 diabetes mellitus. Journal of Diabetes Research 2018 7457269. (https://doi.org/10.1155/2018/7457269)

Zitvogel L, Ayyoub M, Routy B \& Kroemer G 2016 Microbiome and anticancer immunosurveillance. Cell 165 276-287. (https://doi. org/10.1016/j.cell.2016.03.001)

Received in final form 2 April 2021

Accepted 13 April 2021

Accepted Manuscript published online 14 April 2021 (c) 2021 Society for Endocrinology Published by Bioscientifica Ltd. Printed in Great Britain 